\title{
Initiation of Triangle Zones by Delamination, Shear, and Compaction at the Front of Fold-and-Thrust Belts
}

\author{
Chang Liu ${ }^{1,2}$ and Yaolin Shi ${ }^{1}$ \\ ${ }^{1}$ Key Laboratory of Computational Geodynamics, Chinese Academy of Sciences, Beijing, China \\ ${ }^{2}$ Laboratoire de Géologie, CNRS-UMR 8538, École Normale Supérieure, Paris, France
}

Correspondence should be addressed to Chang Liu; liu@geologie.ens.fr

Received 21 July 2015; Accepted 16 December 2015

Academic Editor: Youshun Sun

Copyright (c) 2016 C. Liu and Y. Shi. This is an open access article distributed under the Creative Commons Attribution License, which permits unrestricted use, distribution, and reproduction in any medium, provided the original work is properly cited.

\begin{abstract}
The interest of this paper is to investigate the initiation of triangle zones at the front of fold-and-thrust belts by analyzing the virtual velocity fields in triangle wedges. It allows achieving five collapse mechanisms by delamination, shear, and compaction of competing for the formation of triangle zones as follows. The first mechanism is the classical Coulomb shear thrust. The second is delamination at the frontal part of the décollement with straight back thrust, while the third is delamination with curvy back thrust. The fourth is the combination of ramp with Coulomb shear and shear-enhanced compact fault, while the fifth is the combination of the exchanging motion on the ramp and thrust. The dominating mechanism in the formation of triangle zones relies on the competition of the least upper bound of each mechanism when subjected to tectonic force. The controlling factors of the competition are discovered as follows: (1) the frictional characters and cohesion of horizontal décollements and thrust, (2) the slope of the topography of accretion wedge, and (3) the thickness and rock density of the front toe of accretion wedge.
\end{abstract}

\section{Introduction}

The style of deformation at the front of fold-and-thrust belts is often characterized by triangle zones with forwarddipping ramps (back thrust) (e.g., Southeastern Canadian Cordillera [1] and the foothill of the Longmen Shan [2-5] which is the eastern margin of the Tibetan Plateau). The objective of this paper is to understand the mechanics of three features of the triangle zones which are summarized in the prototype presented in Figure 1. This prototype is a triangle wedge with an accretion layer at its front. The first of the three features of interest is the change in décollement from the basal plane of our prototype to an upper décollement, thanks to the activation of a short ramp connecting the two planar surfaces. Second, there is delamination of the upper décollement starting at the point of intersection with the short ramp and along a segment of unknown length. The right end of this segment is the centre of rotation responsible for the delamination. The third feature is the curvature of the fault emanating from the upper décollement. These deformation mechanisms required either shear, opening, or compaction of velocities discontinuities which are highlighted in the same figure. The proposition for this prototype comes from the following review of the literatures on triangle zones.

Charlesworth and Gagnon [6] studied the Rocky mountains foothills of Central Alberta. They noticed the stacking of horses resulting in a duplex within the internal part of the triangle zone, also called the tectonic wedge, the region bounded by the lower décollement and our curvy back thrust. We shall not consider the formation of this series of horses and dissipation is accounted for solely along the shear plane rooting on the lower décollement tip. These authors suggested that the development of the duplex is accompanied by the initiation of the back-thrusting of the upper sedimentary layer. That argument seems difficult to justify from a mechanical point of view if Coulomb materials are considered. It is believed that the vergence of the thrusting system on the upper décollement should be towards the foreland and not hinterland. One of the objectives of this paper is to appeal to rock rheology to justify the interpretation of Charlesworth and Gagnon [6]. 


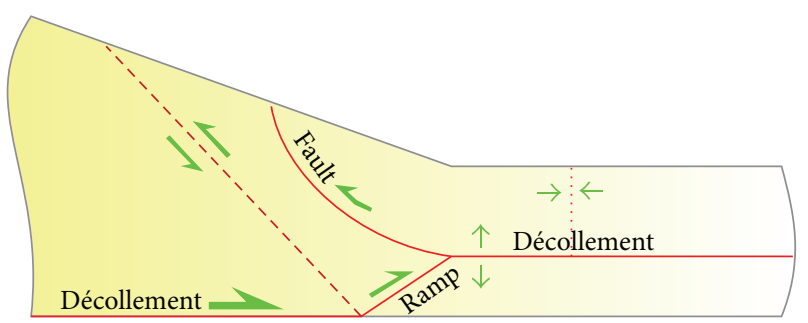

FIGURE 1: This prototype summarizes the three features of the triangle zones which are studied: the change in depth of the décollement, the delamination of the upper décollement, and the curving of the fault (back thrust). These deformation mechanisms require a combination of slip, opening, and compaction on the various velocity discontinuities.

Price [1] provided several examples from the Canadian Rockies where the tectonic wedge results from the activation of thrust splaying from the lower décollement and resulting in the thickening of the tectonic wedge and the prying upward of the hinterland verging upper thrusting layer. Thrust folds in the tectonic wedge are also mentioned as well as the absence of change in depth of the décollement. Price mentioned the concept of delamination of the allochthonous frontal sediments along weak interface suggesting our proposal to account for weak tensile strength in our mechanical prototype. The hinterland vergence of the upper thrusting system is justified by Price as the selection of a conjugate shear failure plane in a compression test done in the laboratory. This argument, already present in the analysis of Charlesworth and Gagnon [6], is certainly central to our analysis. Note that Price [1] proposed that the delamination process could also occur at the much larger scale of the lithosphere, the lower décollement being within, or at the base of the crust. This kind of deep crust lower décollement is detected to be existing at the bottom of the upper crust beneath the eastern Tibetan margin to form the lower décollement of the triangle zone [2].

Jamison [7] defined that a triangle zone is the area bounded by a back thrust at the foreland margin of the thrust belt, a floor thrust that terminates up dip at the back thrust, and the most proximal thrust (on the hinterland side of the reference back thrust) that reaches the erosional surface. Jamison is interested in the longevity of the back thrust which could be terminated by a foreland thrusting through the upper sedimentary layer or by the initiation of a new back thrust more frontal: the triangle zone is abandoned for a new one. Jamison invoked the minimum dissipation argument to select the best scenarios but does not have the means to compute the various dissipation sources involved. Because the triangle zone is much smaller than the complete foldand-thrust belt, the cohesion effects are potentially significant through the entire hanging wall of the triangle zone. He used an approximate solution which extends the critical taper theory by accounting for cohesion to decide on the geometry of the back thrust wedge. Our methodology is more rigorous mathematically and will not require any assumptions on the internal state of stress.

Erickson [8] invoked the pinning of the upper décollement to be responsible for the back-thrusting although the mechanical reasons remain unclear. He used finiteelement, Drucker-Prager, and small hardening and needed this pinning of the upper décollement to obtain the stress concentration which could lead to back-thrusting. Note that mesh sensitivity could prevent the strain to localize and thus for this back thrust to be observed.

Couzens and Wiltschko [9] noticed that the mechanical strength of the three units (duplex, roof décollement, and back thrust) of triangle zones is different. The duplex has the same relatively strong strength with the roof décollement, while the overlying cover sequence is weaker. By reconstructing the frontal stratigraphy of the Wyoming thrust belt they suggested that triangle zones may form in the late stages of thrust belt evolution, when significant synorogenic deposits accumulated at the deformation front. It is suggested that the back thrust may be located within the synorogenic deposits, instead of at their base, because the synorogenic deposits often provide the weak shale-rich rocks for the cover sequence to produce back thrust. They appealed to the strength of the cover stratigraphy to determine triangle zones to form in the thrust belt, where the cover sequence is consistently weaker and shakier. Although material strength is used to explain the back thrust preferred to the weak young sediment, the strength of the duplex and the roof décollement are assumed to the same. In this research we will justify how the weak décollement influences the formation of triangle zone.

Jamison [10] used finite-element models to investigate certain mechanical and deformational characteristics of an active triangle zone system by employing converging and nonconverging upper and lower detachment. His results suggested that the frictional characteristics of the upper and lower detachments play a significant role in the distribution of deformation in an evolving triangle zone.

Varsek [11] described that deformed tectonic wedges delaminate the autochthon or upper plate at the flanks of the orogenic prism by interpretation of seismic reflection data from Rocky Mountain fold-and-thrust belt and on the west of the Cascadia subduction zone. Varsek suggested that the tectonic wedges occur at various crustal levels including within the upper crust (e.g., the eastern flank of the Rocky Mountain and coast belts) and at the crust-mantle boundary (e.g., in the interior of the Cascadia subduction zone). This observation indicated that tectonic wedging and delamination are a fundamental feature of crustal deformation.

Couzens-Schultz et al. [12] demonstrated that the strength of the décollements of the intervening and overlying rock layers is the key parameter controlling on the development of passive-roof duplexes (triangle zones) by presenting a series of physical experiments.

Adam et al. [13] studied the mechanics of landward convergent thrusts and its response to rapid sedimentation in the frontal subduction zone of the Cascadia convergent margin using Coulomb frictional wedge analysis, which does not need to invoke very low-basal friction. In this research the taper of the back thrust wedge was defined by the surface slope and the bounding back thrust. It is noticed that all fault segments of the bounding back thrust are active because of the tectonic stresses exceeding the fault strength, since 


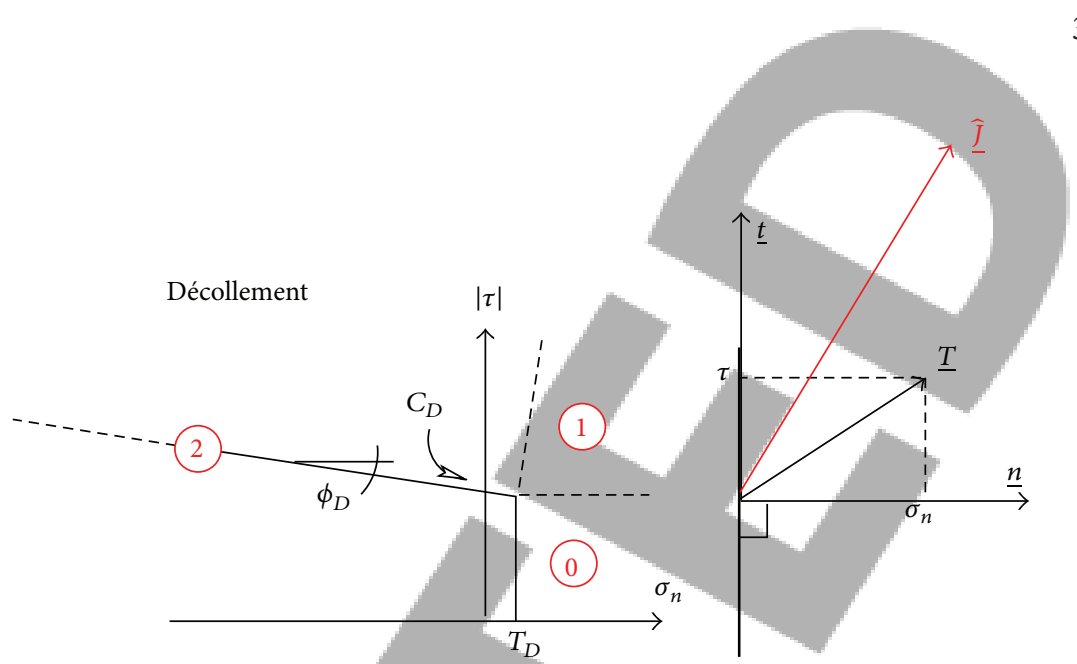

(b)

(c)

FIGURE 2: The bulk material is frictional, cohesive, and compactant. Its compressive strength is set by the maximum compressive strength $P^{*}$ and the compaction angle $\phi^{*}$ (a). The décollement is frictional and dilatant with a maximum tensile strength $T_{D}(\mathrm{~b})$. The two strength domains are presented in the half plane $\left(\sigma_{n},|\tau|\right)$, these two stresses being defined in (c).

dip variations of individual ramp segments between $25^{\circ}$ and $45^{\circ}$ are observable. The back thrust wedge is mechanically stable and can be passively upward delaminated. Adam et al. proposed that the accretion mechanism is controlled by the contrasting mechanical stratigraphy of the thick incoming sediment succession entering the subduction zone rather than by atypical mechanically boundary conditions in the frontal accretionary prism. It is also suggested to explain the mechanics of triangle zone and back thrust wedge at mountain fronts of continental fold-and-thrust belts by Adam et al.

Montanari et al. [14] conducted analogue models and evidenced that the major role in the formation of triangle zone at Vena del Gesso Basin (Romagna Apennines, Italy) is (1) syntectonic erosion that promoted the development of passive-roof duplex style and (2) the role of décollement level pinch-out that determined an oblique progression of deformation.

Tanner et al. [15] pointed out that triangle zones can even occur on a very small as tens of meters scale on the condition that this is supported by the mechanical stratigraphy by studying the siliciclastic Carboniferous strata of the Harz Mountains in northern Germany. This triangle zone exists within a thin high-strain zone within weakly deformed strata. It is suggested that the main controlling factor for the evolution of a triangle zone was the mechanical stratigraphy, which is similar to the proposition by Couzens-Schultz et al. [12] by examining the controlling factors on the large scale triangle zone in fold-and-thrust belt.

The contents of this paper are as follows. Section 2 is devoted to the maximum strength theorem which is classically referred to as the kinematic approach of limit analysis by Salencon [16]. The central idea of this approach is the dualization of the forces acting on the faults and décollement in the sense of power so that the basic unknowns are virtual velocity discontinuities. This dualization has consequences on the selection of the virtual velocities to explore the various regions of the strength domain of interest. These consequences are important to understand the velocity fields considered in this contribution. The first applications of the maximum strength theorem in Sections 3 and 4 are presented for a triangle wedge, which is the most appropriate prototype for a comparison with the critical taper theory of Dahlen [17]. Six velocity fields, describing each collapse mechanism, are presented and put in competition. Section 5 is concerned with the change in depth of the active décollement assuming frictional properties only. The details of the collapse mechanisms at the very front of the wedge are further analyzed in Section 6 where four collapse mechanisms are competing.

\section{The Maximum Strength Theorem}

The name of maximum strength theorem was proposed by Maillot and Leroy [18] to emphasize that the strength properties of the rock are at the core of the approach. This limited rock strength is illustrated for the bulk material and for the material composing the décollement in Figure 2. The stress space is spanned by the normal stress $\sigma_{n}=\underline{T} \cdot \underline{n}$ and the tangential stress $\tau=\underline{T} \cdot \underline{t}$ in which $\underline{n}$ and $\underline{t}$ are the normal and tangent vector orienting the facet on which the stress vector $T$ is acting (Figure 2(c)). The continuum convention sign is adopted: compressive normal stress is negative. The two strength domains share a common feature which is the boundary set by the Coulomb line defined by the friction angle $\phi$ or $\phi_{D}$ and the cohesion $C$ or $C_{D}$. The bulk material is porous and could compact under sufficiently large compressive stresses. This limit in compression is defined by the maximum compressive strength $P^{*}$. This compaction is enhanced by the shear on the facet and a simple linear relation is proposed to close the strength domain in compression, characterized by the compaction angle $\phi^{*}$. The material within the décollement does not have this limit in 
compressive strength and the strength domain remains open in compression. The décollement material is weak compared to the bulk material and its friction angle $\phi_{D}$ will be assumed smaller than $\phi$. This material has also a finite tensile strength $T_{D}$ which could be small favoring the delamination of the upper décollement, a characteristic of the triangle zone.

The maximum strength theorem relies on a dualization of the stress problem and the conjugate quantities, in the sense of mechanical power, are velocities. Velocity fields are proposed which characterizes the initiation of the structure collapse and more precisely which part of the strength domain boundary could be attained. Consider, for example, the velocity jump $\widehat{J}$ over the facet in Figure 2(c): its orientation with respect to the normal to the fact determines which part of the strength domain boundary, numbered from 0 to 6 , could be probed. For example, if the velocity jump is a pure opening mode (oriented along $\underline{n}$ ), the relevant region is numbered 0 . If this orientation is $-\underline{n}$, the stress space probed is in pure compaction, region 6 . Region 2 corresponds exactly to the angle $\pi / 2-\phi$ between the velocity jump and the normal and defines slip on the fault according to Coulomb. Shear-enhanced compaction, region 4 , corresponds to the angle $\pi / 2+\phi^{*}$. There are two additional regions 1 and 3 corresponding to the simultaneous activation of opening and shear and of shear-enhanced compaction and Coulomb shear. Note that the décollement can only sustain jumps which is oriented according to cases 0 to 2 . A formal introduction of the rationale behind this theory is found in Salencon [16], and has been presented in Maillot and Leroy [18] and also in a geological context by Cubas et al. [19]. The details of the conditions relating the velocity and the regions on the strength domain boundary are presented again in Appendices for sake of completeness. It contains also all the calculations leading to the least upper bounds presented in this contribution. We shall concentrate solely on the presentation of the velocity field and, more precisely, on the potential collapse mechanisms defined by these velocity fields and at the origin of the instantaneous deformation of the wedge.

\section{Triangle Wedge: Six Collapse Mechanisms in Competition}

The motivation for proposing each mechanism and the associated upper bound $Q_{\mathrm{u}}^{i}$ are provided in this section. The details of the calculations are postponed to Appendices. The maximum strength theorem ensures that the smallest of the six upper bounds is associated with the dominant mode of collapse. This comparison is presented in the next section.

3.1. Mechanism Numbers 1 and 2: For Comparison with the Critical Taper Theory. Collapse mechanism number 1 is the simplest and should be dominant for super-critical slopes if only friction prevails. It consists of the gliding of the whole wedge on the décollement (Figure 3(a)). The maximum strength theorem provides the upper bound to the applied force

$$
Q_{\mathrm{u}}^{(1)} \cos \phi_{D}=C_{D} \cos \phi_{D} L_{A B}+\rho g \sin \left(\phi_{D}+\beta\right) S_{A B C},
$$

where $L_{A B}$ and $S_{A B C}$ stand for the total length of the décollement and the surface of the wedge, respectively. In what follows, subscripts are sets of two points or one or two letters which identify the lengths, the surfaces, or the material properties. Note that the upper bound is not a function of any free variable which, typically, would be optimized to obtain the least upper bound. In this sense, (1) is also the least upper bound $Q_{\mathrm{lu}}^{(1)}$.

Collapse mechanism number 2 is a thrust fold which partitions the wedge into three regions (Figure $3(\mathrm{~b})$ ). The region $G E F$ is the hanging wall (HW) which is moving forward over the fault GE. Material in the region $A G F C$, called the back stop (BS), is gliding over the décollement activated between points $A$ and $G$. The toe region $G B E$ is at rest with respect to the observer. Note that the vergence of the hanging wall is not identified. The two faults $G E$ and $G F$, oriented by the angles $\theta_{G E}$ and $\theta_{G F}$, respectively, play identical role in this theory. They can act either as a ramp and shear plane (foreland vergence) or as a shear plane and a ramp (hinterland vergence) or finally as two ramps (pop-up structure). The application of the maximum strength theorem provides

$$
\begin{aligned}
& Q_{\mathrm{u}}^{(2)} \cos \phi_{D}=\rho g\left(S_{\mathrm{BS}} \sin \left(\phi_{D}+\beta\right)\right. \\
& \left.\quad+\widehat{U}_{\mathrm{HW}} S_{\mathrm{HW}} \sin \left(\phi_{\mathrm{GE}}+\theta_{\mathrm{GE}}+\beta\right)\right)+L_{A G} C_{D} \cos \phi_{D}
\end{aligned}
$$

$$
+C_{G F} L_{G F} \widehat{J}_{G F} \cos \phi_{G F}+C_{G E} L_{G E} \widehat{U}_{\mathrm{HW}} \cos \phi_{G E} \text {. }
$$

The norm of the velocity $\widehat{U}_{\text {HW }}$ of the hanging wall and of the jump $\widehat{J}_{G F}$ over the fault $G F$ is related by

$$
\begin{aligned}
\frac{\widehat{U}_{\mathrm{HW}}}{\sin \left(\phi_{D}+\phi_{G F}+\theta_{G F}\right)} & =\frac{\widehat{J}_{G F}}{\sin \left(\phi_{G E}+\theta_{G E}-\phi_{D}\right)} \\
& =\frac{1}{\sin \left(\theta_{G F}+\theta_{G E}+\phi_{G F}+\phi_{G E}\right)} .
\end{aligned}
$$

The upper bound in (2) is a function of three parameters, the two faults angles $\theta_{G E}$ and $\theta_{G F}$ as well as the distance $L_{A G}$. It is the minimum value of (2) which is of interest and the associated optimum values of these three parameters. The minimum load is then the least upper bound $Q_{\mathrm{lu}}^{(2)}$. For that minimization, we follow Cubas et al. [19] and discretize the topography and the décollement and select the optimum position of the three points $E, F$, and $G$ (see Figure $3(\mathrm{~b})$ for definition).

This second mechanism is proposed for comparison sake with the critical taper theory for a purely frictional material. The distance $L_{A G}$ should be small and thus the thrust fold at the back for subcritical conditions $\left(\alpha<\alpha_{c}\right)$ and equal to the distance $L_{A B}$, for super-critical conditions $\left(\alpha>\alpha_{c}\right)$ since the deformation is then to the front. In the latter case the first and second collapse mechanisms are identical.

3.2. Mechanism Number 3: Delamination on the Frontal Part of the Décollement. Collapse mechanism number 3 is the first to be proposed for exploring the possibility for the frontal part of the décollement to delaminate, a basic mechanism observed 


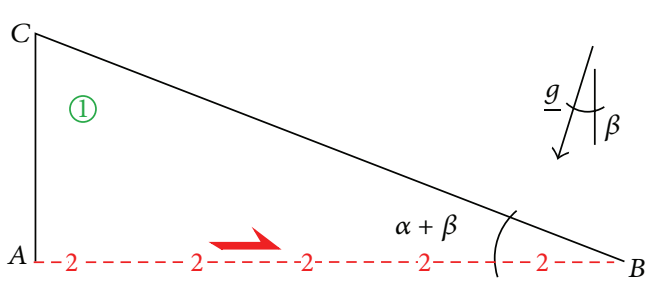

(a)

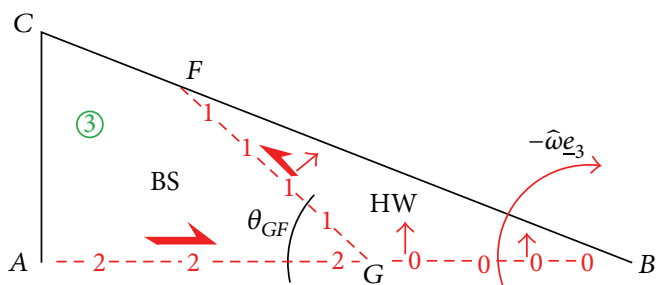

(c)

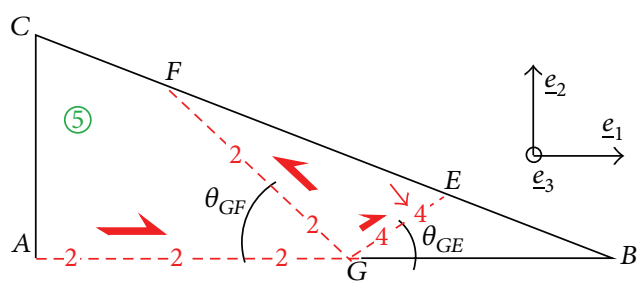

(e)

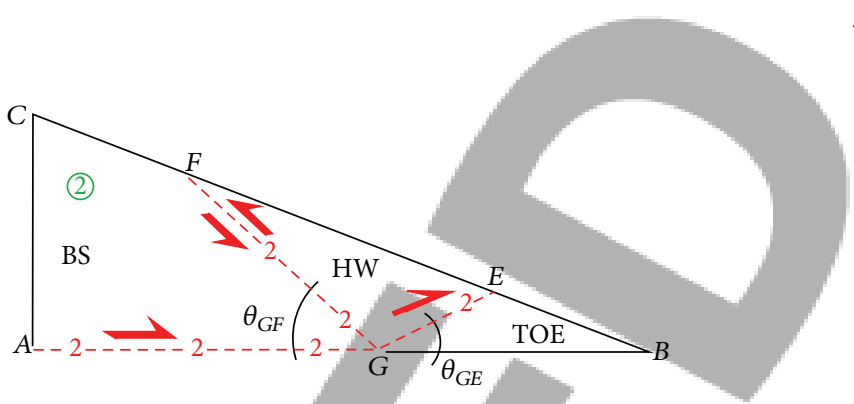

(b)

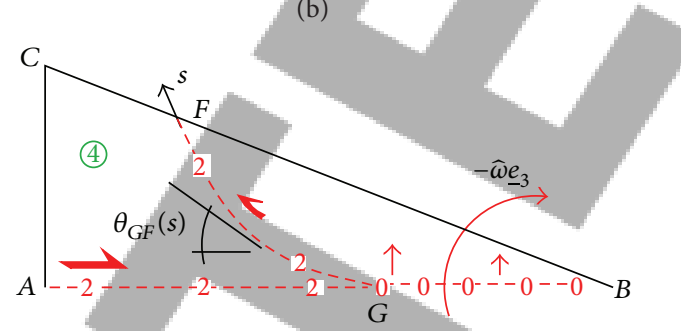

(d)

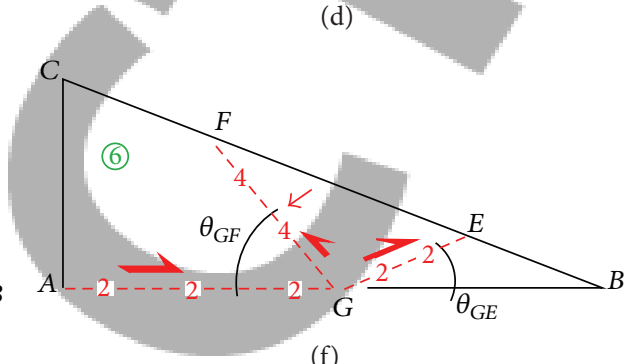

(f)

FIgURE 3: The six collapse mechanisms in competition: the complete gliding on the décollement in (a), the classical frictional thrust fold for comparison with the critical taper theory (b), the delamination mechanism with a straight fault (c) and a curvy fault (d), and finally the compacting thrust fold to promote hinterland (e) and foreland vergence (f). The numbers $0,1,2$, and 4 identify the regions of the strength domain activated and are defined in Figure 2.

in most triangle zones (Figure 3(c)). The wedge is partitioned into two regions, the first region being the back stop AGFC gliding on the section $A G$ of the décollement. The second region is the hanging wall $G B F$ which sustains a rigid rotation $\widehat{\omega}$ around the point $B$ as illustrated in Figure 3(c).

The décollement between points $A$ and $G$ is sheared whereas points between $G$ and $B$ have a velocity normal to the décollement and proportional to the distance to point $B$, corresponding to the delamination process. The angular velocity $\widehat{\omega}$ is chosen such that the jump in velocity at point $G$ between the fault $G F$ and the back stop (norm $\widehat{J}_{G}$ ) is probing the strength domain in region 2 . The other points on the fault $G F$ are in region 1, meaning that the fault GF sustains a mixed mode of shearing and opening. The upper bound to the tectonic force is

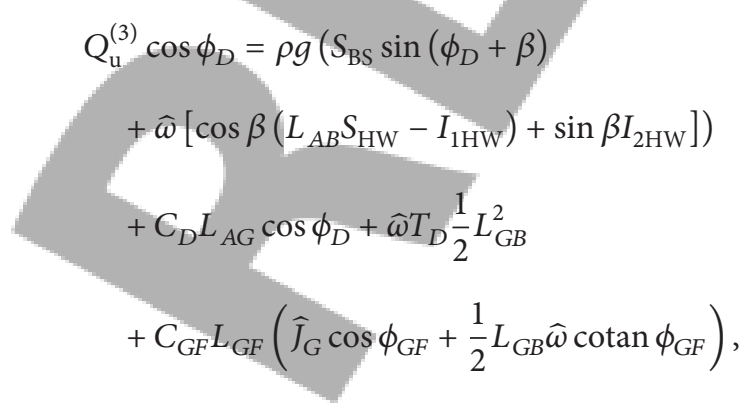

$$
\begin{aligned}
& 6 I_{1 \mathrm{HW}}=\left(L_{A B}^{3}-\left[L_{A B}-x_{2 F} \operatorname{cotan}(\alpha+\beta)\right]^{3}\right) \\
& \cdot \tan (\alpha+\beta)-\left(L_{A G}^{3}-\left[L_{A G}-x_{2 F} \operatorname{cotan} \theta_{G F}\right]^{3}\right) \\
& \cdot \tan \theta_{G F}, \\
& 6 I_{2 \mathrm{HW}}=x_{2 F}^{3}\left[\operatorname{cotan}(\alpha+\beta)-\operatorname{cotan} \phi_{G F}\right]
\end{aligned}
$$

in which $x_{2 F}, I_{1 \mathrm{HW}}$, and $I_{2 \mathrm{HW}}$ are the second coordinate of point $F$ and the moment of the hanging wall with respect to the first and second axis, respectively. The norm of the velocity jump at point $G$ and the angular velocity is related by

$$
\frac{\widehat{\omega} L_{A B}}{\sin \left(\phi_{D}+\phi_{G F}+\theta_{G F}\right)}=\frac{1}{\cos \left(\phi_{G F}+\theta_{G F}\right)}=\frac{\widehat{J}_{G}}{\cos \phi_{D}} .
$$

This upper bound is the function of the length $L_{A B}$ and the angle $\theta_{G F}$. These two parameters are varied making use of the same spatial discretization of the topography and the décollement as for mechanism number 2. There is an optimum set of points $(G, F)$ for which $Q_{\mathrm{u}}^{(3)}$ in (4) is minimum and this value is denoted as $Q_{\mathrm{lu}}^{(3)}$. 
This collapse mechanism has the merits of its geometrical simplicity with the drawback that the fault $G F$ is in a slip mode only at point $G$ and is in a mixed mode of slip and opening along GF by construction. This mode of deformation is certainly not very realistic and the next collapse mechanism is hoped to improve on this deficiency.

\subsection{Mechanism Number 4: Delamination with a Curved Fault.} Mechanism number 4, the second to account for delamination, proposes a curved fault which separates the wedge into two velocity regions. The fault is tangent to the décollement at point $G$, and its curvature is such that Coulomb friction is activated all along (Figure 3(d)). The hanging wall is rotating around point $B$ such that the section $G B$ of the décollement is delaminated, as for collapse mechanism number 3 . This fault geometry is computed with a second-order asymptotic development in the arc length $s$, parameter of the fault from point $G$ to $F$. The application of the maximum strength theorem then provides the following upper bound:

$$
\begin{gathered}
\int_{0}^{s_{F}} \widehat{J}_{G F}\left(s^{\prime}\right) d s^{\prime}, \\
I_{1 \mathrm{HW}}=\int_{\mathrm{HW}} x_{1} d s, \\
I_{2 \mathrm{HW}}=\int_{\mathrm{HW}} x_{2} d s, \\
\widehat{\omega} L_{A B}=\frac{\sin \left(\phi_{D}+\phi_{G F}\right)}{\cos \phi_{G F}},
\end{gathered}
$$$$
Q_{\mathrm{u}}^{(4)} \cos \phi_{D}=\rho g\left(S_{\mathrm{BS}} \sin \left(\phi_{D}+\beta\right)\right.
$$$$
\left.+\widehat{\omega}\left[\cos \beta\left(L_{A B} S_{\mathrm{HW}}-I_{1 \mathrm{HW}}\right)+\sin \beta I_{2 \mathrm{HW}}\right]\right)
$$$$
+C_{D} L_{A G} \cos \phi_{D}+\widehat{\omega} T_{D} \frac{1}{2} L_{G B}^{2}+C_{G F} \cos \phi_{G F}
$$

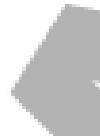

(6)

in which $\widehat{J}_{G F}$ and $s_{F}$ are the norm of the velocity jump over $G F$ and the arc length $s$ measured at point $F$. The moments $I_{1 \mathrm{HW}}, I_{2 \mathrm{HW}}$, the surface $S_{\mathrm{HW}}$, and any integral are estimated by numerical means. The angle $\theta_{G F}(s)$, defining the orientation of the tangent to the fault at any $s$ (see illustration in Figure 3(d)), is obtained from the condition that the fault is always in case 2

$$
\begin{aligned}
\tan \left(\theta_{G F}(s)+\phi_{G F}\right)= & -\frac{\widehat{J}_{G F 2}}{\widehat{J}_{G F 1}} \\
\text { with } \widehat{J}_{G F}(\underline{x})= & -\left(\cos \phi_{D}-\widehat{\omega} x_{2}\right) \underline{e}_{1} \\
& +\left[\widehat{\omega}\left(L_{A B}-x_{1}\right)-\sin \phi_{D}\right] \underline{e}_{2},
\end{aligned}
$$

in which $\left(x_{1}, x_{2}\right)$ are the coordinates of the point on the fault $G F$ at the arc length $s$.

The minimization of the upper bound in (6) is conducted by computing for every point $G$ on the descritized décollement and point $F$ on the descritized décollement. The associated least upper bound is denoted as $Q_{\mathrm{lu}}^{(4)}$.
3.4. Mechanism Numbers 5 and 6: Compaction and Thrusting. The last two collapse mechanisms are proposed to break the symmetric role of the two faults $G E$ and $G F$ in mechanism number 2 . This symmetry breaking is done by assuming that one of the faults is a ramp and deforming by Coulomb shear (region 2) whereas the material crossing the other fault is shear-enhanced compacted (region 4) (Figures 3(e) and 3(f)). The ramp is shearing repeatedly the same material and compaction cannot be the relevant deformation mechanism. On the contrary, the conjugate plane is crossed by new material constantly and this material could compact during its shearing.

These collapse mechanisms number 5 and number 6 are explored assuming that the compaction strength $P^{*}$ in the bulk is not homogeneous but sustains a gradient typical of the compaction in a sedimentary basin. The necessity for this proposition is documented in the next section. This gradient is assumed to be a constant vector normal to the topography $\underline{\nabla P^{*}}=G^{*} \underline{N}$, where $\underline{N}$ is the normal to the topography pointing externally and $\bar{G}^{*}$ is the gradient norm. The compaction strength at any point within the wedge pointed by the vector $\underline{x}$ is then $P^{* 0}+\underline{\nabla P^{*}} \cdot\left(\underline{x}_{C}-\underline{x}\right)$ taking the point $C$ as a reference point and $P^{* 0}$ standing for the surface value of the compaction strength. The application of the maximum strength theorem provides the two upper bounds:

$$
\begin{aligned}
& Q_{\mathrm{u}}^{(5)} \cos \phi_{D}=\rho g\left(S_{B C} \sin \left(\phi_{D}+\beta\right)\right. \\
& \left.+\widehat{U}_{\mathrm{HW}} S_{\mathrm{HW}} \sin \left(\theta_{G E}-\phi_{G E}^{*}+\beta\right)\right)+L_{A G} C_{D} \cos \phi_{D} \\
& +C_{G F} L_{G F} \widehat{J}_{G F} \cos \phi_{G F}+\widehat{U}_{\mathrm{HW}} \sin \phi_{G E}^{*} \\
& \cdot\left(L_{G E}\left[P_{G E}^{* 0}+\underline{\nabla P}_{G E}^{*} \cdot\left(\underline{x}_{C}-\underline{x}_{G}\right)\right]-\frac{1}{2} L_{G E}^{2} \underline{\nabla P}_{G E}^{*}\right. \\
& \left.\cdot \underline{t}_{G E}\right), \\
& Q_{\mathrm{u}}^{(6)} \cos \phi_{D}=\rho g\left(S_{B C} \sin \left(\phi_{D}+\beta\right)\right. \\
& \left.+\widehat{U}_{\mathrm{HW}} S_{\mathrm{HW}} \sin \left(\theta_{G E}+\phi_{G E}+\beta\right)\right)+L{ }_{A G} C_{D} \cos \phi_{D} \\
& +C_{G E} L_{G E} \widehat{U}_{\mathrm{HW}} \cos \phi_{G F}+\widehat{J}_{G F} \sin \phi_{G F}^{*} \\
& \cdot\left(L_{G F}\left[P_{G F}^{* 0}+\underline{\nabla P}_{G F}^{*} \cdot\left(\underline{x}_{C}-\underline{x}_{G}\right)\right]-\frac{1}{2} L_{G F}^{2} \underline{\nabla P_{G F}^{*}}\right. \\
& \left.\cdot \underline{t}_{G F}\right),
\end{aligned}
$$

where $\underline{t}_{G F}$ and $\underline{t}_{G E}$ are the unit vectors tangent to the fault indicated in subscript and oriented from $G$ towards the free surface. The velocity norms in (8) and (9) are defined by

$$
\text { no 5: } \begin{aligned}
& \frac{\widehat{J}_{G F}}{\sin \left(\theta_{G E}-\phi_{G E}^{*}-\phi_{D}\right)} \\
& =\frac{1}{\sin \left(\theta_{G F}+\phi_{G F}+\theta_{G E}-\phi_{G E}^{*}\right)} \\
& =\frac{\widehat{U}_{H W}}{\sin \left(\theta_{G F}+\phi_{G F}+\phi_{D}\right)},
\end{aligned}
$$




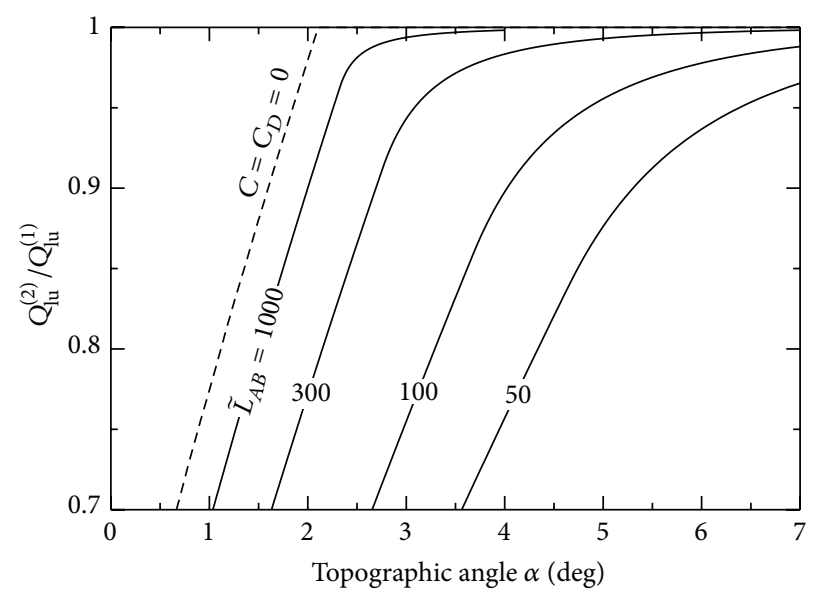

(a)

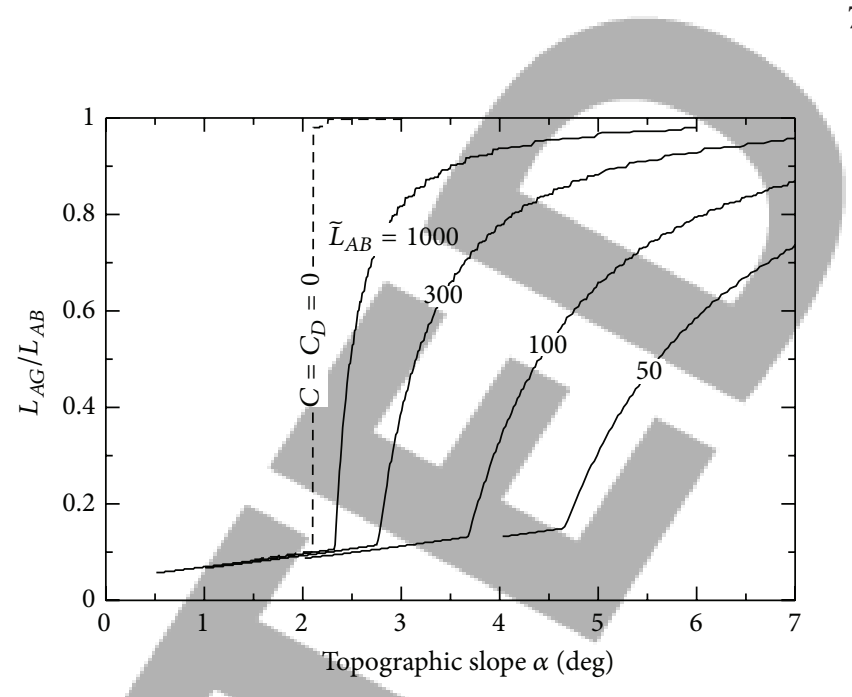

(b)

FIGURE 4: Influence of the length $L_{A B}$ on the cohesive wedge stability and comparison with the cohesionless case (dashed curve). The ratio of the least upper bounds (mechanisms 2 and 1) is presented in (a) and the extent of the activated décollement in (b). The jump for the cohesionless wedge at the critical taper slope $\alpha_{c}$ is replaced by a smooth transition of the thrust fold root from the back to the front if cohesion is accounted for.

no 6:

$$
\begin{aligned}
& \frac{\widehat{J}_{G F}}{\sin \left(\theta_{G E}+\phi_{G E}-\phi_{D}\right)} \\
& =\frac{1}{\sin \left(\theta_{G F}-\phi_{G F}^{*}+\theta_{G E}+\phi_{G E}\right)} \\
& =\frac{\widehat{U}_{H W}}{\sin \left(\theta_{G F}-\phi_{G F}^{*}+\phi_{D}\right)} .
\end{aligned}
$$

The minimization of (8) and (9) is done as for mechanism number 2: the load is computed for every set of points $(E, F$, and $G$ ) and the selected set is the one leading to the minimum bounds $Q_{\mathrm{lu}}^{(5)}$ and $Q_{\mathrm{lu}}^{(6)}$.

\section{Triangle Wedge: Stability Predictions}

The following dimensional analysis is proposed. The reference stress $\sigma_{R}$ is taken equal to the bulk cohesion $C$ set to $10 \mathrm{MPa}$. The material weight $\rho g$ is $25 * 10^{4} \mathrm{~Pa} / \mathrm{m}$ so that the ratio $\rho g / \sigma_{R}$ provides the characteristic length $L_{R}=$ $400 \mathrm{~m}$. Material and geometrical parameters are summarized in Table 1. Dimensionless quantities will be noted with a superposed tilde; for example, $\widetilde{L}_{A B}=L_{A B} / L_{R}$.

4.1. Comparison with the Critical Taper Theory: Mechanism Numbers 1 and 2. The first objective is to compare the predictions of the collapse mechanism numbers 1 and 2 with the critical taper theory. The ratio of least upper bounds $Q_{\mathrm{lu}}^{(2)} / Q_{\mathrm{lu}}^{(1)}$ is presented as a function of the topographic angle $\alpha$ in Figure 4(a). The distance from the back wall to the root of the thrust fold $L_{A G}$ is seen in Figure 4(b). The dashed curves correspond to the cohesionless wedge that is first analyzed. The ratio is increasing approximately linearly for small values of the topographic angle, and the distance $L_{A G}$
TABLE 1: Geometrical and material properties for the triangle wedge and the six collapse mechanisms presented in Figure 3 unless they are varied (var.) in the analysis.

\begin{tabular}{llcc}
\hline Symbol & Definition & Value & Unit \\
\hline$\beta$ & Décollement dip & 2 & $\mathrm{deg}$ \\
$\rho g$ & Material unit weight & 2500 & $\mathrm{~Pa} / \mathrm{m}$ \\
$\phi$ & Bulk friction angle & 30 & $\mathrm{deg}$ \\
$\phi^{*}$ & Bulk compaction angle & 40 & $\mathrm{deg}$ \\
$C$ & Bulk cohesion & 10 & $\mathrm{MPa}$ \\
$P^{* 0}$ & Bulk compaction strength at surface & Var. & $\mathrm{MPa}$ \\
$G^{*}$ & Bulk compaction strength gradient & Var. & $\mathrm{MPa}$ \\
$\phi_{D}$ & Décollement friction angle & 10 & $\mathrm{deg}$ \\
$C_{D}$ & Décollement cohesion & Var. & $\mathrm{MPa}$ \\
$T_{D}$ & Décollement tensile strength & 0 & $\mathrm{MPa}$ \\
\hline
\end{tabular}

is small compared to $L_{A B}$, which signals that the optimum thrust folds for each $\alpha$ is rooting at the back of the wedge, as expected for subcritical slope conditions $\left(\alpha<\alpha_{c}\right)$. The force ratio is equal to one exactly for the topographic slope $\alpha_{c}=2.106$ predicted by the critical taper theory. The length $L_{A G}$ for $\alpha_{c}$ is indeterminate and jumps from a small value to a value close to $L_{A B}$. The position of the thrust fold cannot be anywhere within the wedge. For larger $\alpha$, the force ratio is one meaning that the whole wedge is gliding on the décollement and the deformation is indeed found at the front, limited by the numerical discretization. The topographic conditions are thus super-critical $\left(\alpha>\alpha_{c}\right)$. Mechanism numbers 1 and 2 are thus in agreement with the classical taper theory for cohesionless wedges.

The stability prediction accounting for cohesion is presented in the same two figures with $\widetilde{C}_{D}=\widetilde{C}=1$. The wedge length $L_{A B}$ is varied between 50 and 1000 times the 


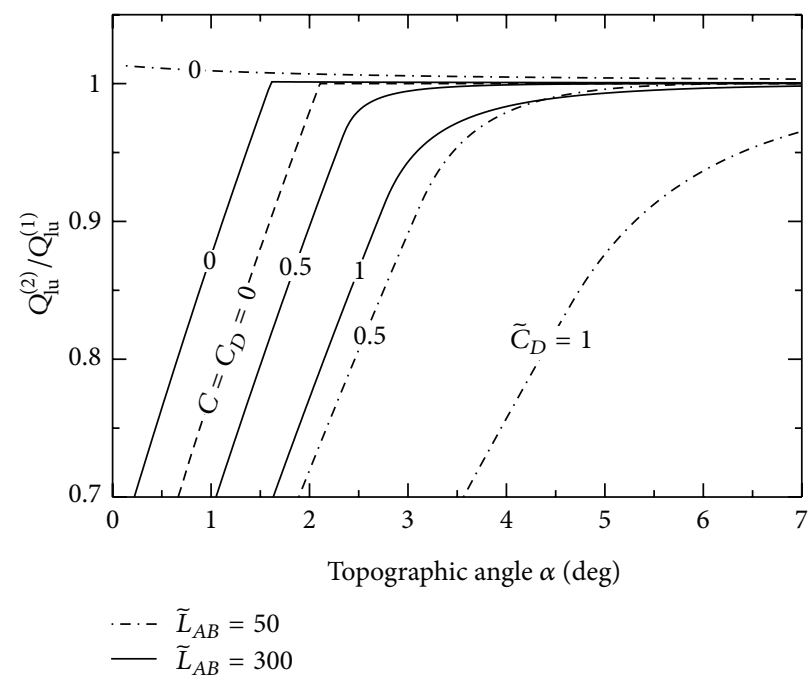

(a)

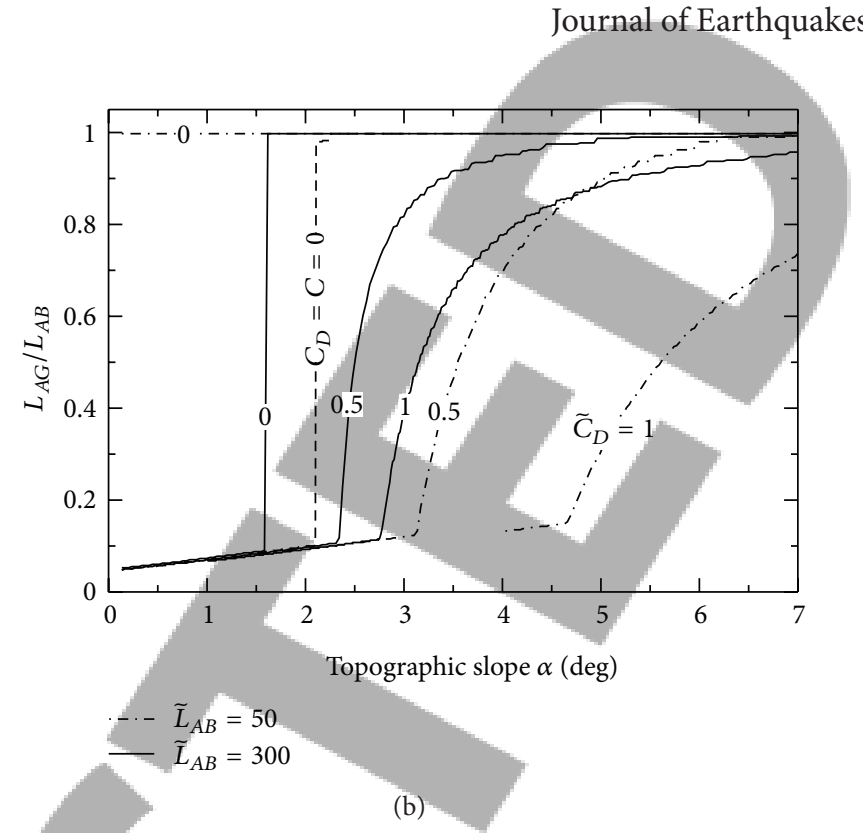

(b)

FIGURE 5: Influence of the décollement cohesion on the cohesive wedge stability for two lengths $\widetilde{L}_{A B}=50$ and 300 in dotted-dashed and solid curves, respectively. The results for the cohesionless wedges are the dashed curves.

reference length $L_{R}$ of the problem. The first observation is that the force ratio is not anymore a bilinear function of the topographic slope. There is a gradual transition from the approximately linear relation for small $\alpha$ to the horizontal asymptote at one for large values of $\alpha$. This transition is smoother for the smaller values of $\widetilde{L}_{A B}$. In the limit of $\widetilde{L}_{A B}$ tending to infinity, the solution converges towards the results obtained in the absence of cohesion. The smooth transition from subcritical to super-critical conditions is due to the progressive migration of the dominant thrust fold from the rear to the front of the wedge with increasing values of $\alpha$. Note that this transition is not activated at $\alpha_{c}$ but with a definite delay which is increasing for the smaller values of $\widetilde{L}_{A B}$.

The cohesion of the décollement is now varied with respect to bulk material cohesion for the two values of the length $\widetilde{L}_{A B}$ of 50 and 300 . The results are presented in Figure 5. Consider first the results for $\widetilde{L}_{A B}=50$, the dotteddashed curves presented for $\widetilde{C}_{D}=1,0.5$, and 0 . Reducing the cohesion by half has shifted the curve of the bound ratio towards the critical taper solutions. There is still a delay in the beginning of the smooth transition of the root $G$ from the rear to the front of the wedge but this delay is reduced by half (Figure $5(\mathrm{~b})$ ). The next value of the décollement is $C_{D}=0$, and in that instance the least upper bound for the second mechanism is always greater than one. This limit of one is exceeded because of the numerical discretization but the important result is that the cohesive wedge on the cohesionless décollement with $\widetilde{L}_{A B}=50$ is always supercritical. This conclusion is confirmed by the length of the activated décollement, which is found to be equal to the total length of the wedge (Figure 5(b)). Complementary results are presented or the length $\widetilde{L}_{A B}=300$, solid curves. The new information is that the bound ratios for $\widetilde{C}_{D}=0.5$ and 0 are around the critical taper solutions. Note that the stability

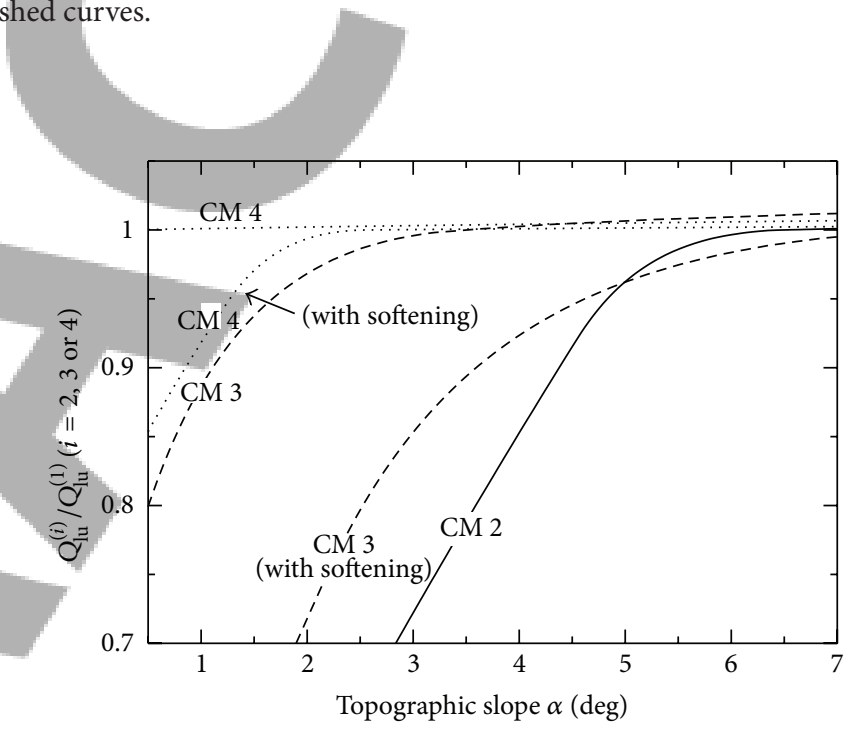

Figure 6: Comparison of the bounds for collapse mechanisms for thrusting (CM 2), solid line, for delamination with a straight fault (CM 3), dashed curves, and delamination with a curved ramp (CM 4). The wedge length is $\widetilde{L}_{A B}=10$ and the softening for the delamination mechanisms is such that the fault GF has the properties of the décollement instead of the bulk material.

transition or the cohesionless décollement occurs for an angle approximately $0.5^{\circ}$ less than for the critical taper theory.

4.2. Delamination: Mechanism Numbers 3 and 4. The first observation is that the delamination mechanisms are always to the front of the triangle wedge and can only compete with thrusting mechanism number 2 for wedge sufficiently small. Results are presented for $\widetilde{L}_{A B}=10$ in Figure 6. The first results were obtained assuming the straight or curvy fault GF had the properties of the bulk material. The ratio of bounds for CM 3 and 4 was always larger than the ratio for the classical thrusting CM 2. Moreover, the CM 3 which 


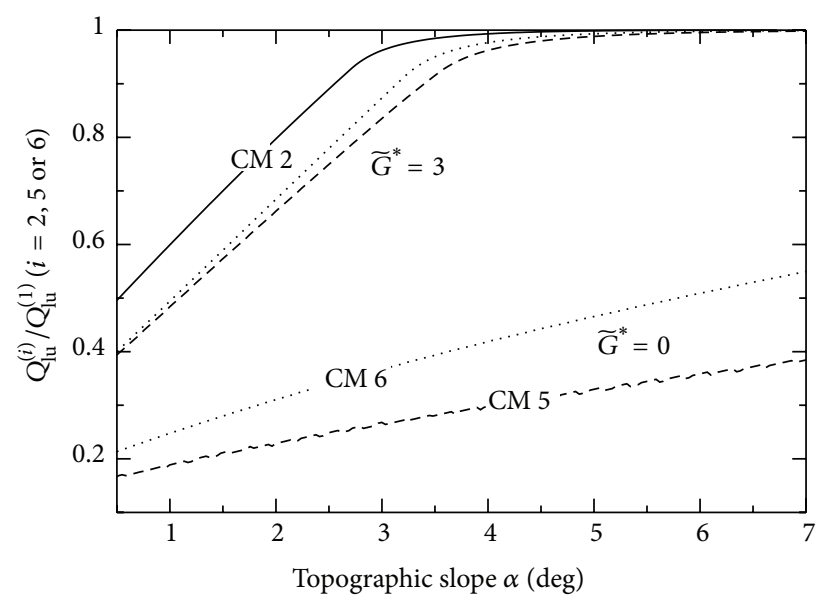

(a)

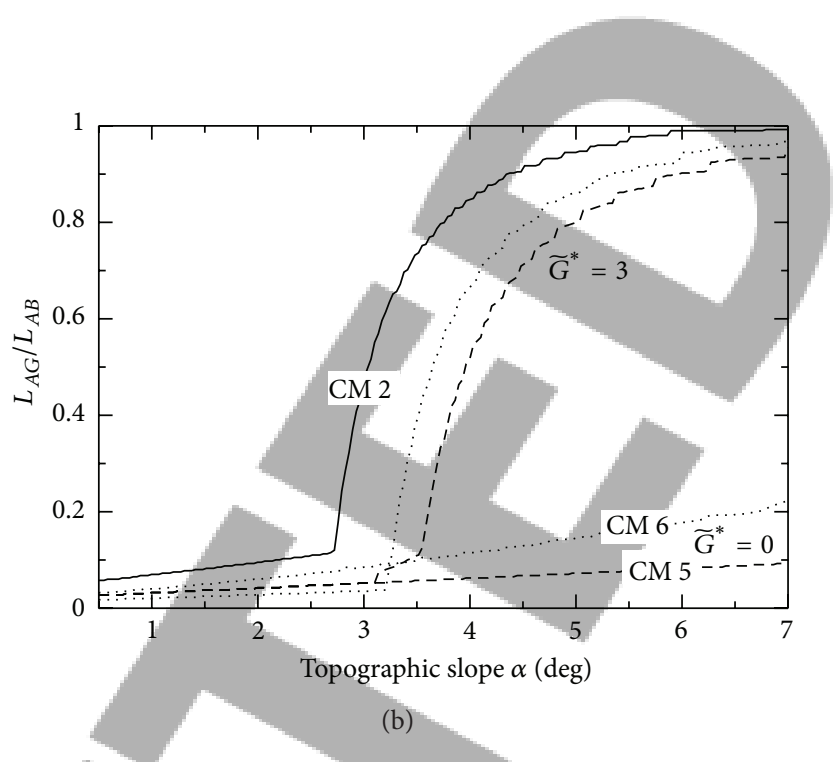

Figure 7: Comparison of collapse mechanism numbers 5, 6, and 2, to question the thrusting vergence, in terms of the bound ratio, (a) and the position of the $\operatorname{root} G$ on the décollement, (b). Results obtained for $\widetilde{L}_{A B}=100$.

is supposed to improve on CM 2 was always super-critical, positioned to the very front of the triangle wedge and with a bound ratio equal to one. A second set of stability predictions were obtained by introducing some softening on the fault $G F$. It was assigned, for sake of simplicity, the same properties as the décollement. The results are more satisfactory in the sense that CM 3 dominates CM 2 for $\alpha$ greater than approximately $5^{\circ}$, approximately. The $\operatorname{root} G$ is at the dimensionless distance of 8 and 5, respectively, for this specific angle. Mechanism number 4 is already super-critical and found at the tip of the wedge.

4.3. Compaction and Thrusting: Mechanism Numbers 5 and 6. The comparison between CM 5, 6, and 2 is proposed to question the vergence of the thrusting. Results are presented in Figure 7 for $\widetilde{L}_{A B}=100$. Two sets of results are presented, the first in the absence of compaction gradient $\widetilde{G}^{*}=$ 0 and the second with a gradient of 3 . The first set of results are interesting since they show that the two thrusting mechanisms with compaction dominate with a preference for mechanism number 5 proposed for a hinterland vergence. Nevertheless, the position of the root (point $G$ ) of this mechanism is at the back of the wedge for all topographic angles. Introducing a gradient $\widetilde{G}^{*}$ has the definite advantage that there is a stability transition which is rather close to the one recorded for classical mechanism number 2 with a delay in transition not exceeding $1^{\circ}$. The ratio of bound is still in favor of the two compacting mechanisms with a slight advantage for mechanism number 5 which promotes hinterland vergence.

\section{Two Décollements and an Accretion Front}

The objective of the next two sections is to account for the presence of an accretion front to our triangle wedge. This section focuses on the potential change in décollement activation which is often observed at the front of fold and thrust belts. Only frictional properties are considered here (region 2 of the strength domain) and the contributions of delamination, opening, and compaction are examined in the next section with a simplified prototype.

The front of our wedge is presented in Figure 8(a) where the lower décollement is at the base on the accretion layer of thickness $H$ with properties $\left(\phi_{D}, C_{D}\right)$. The length of the wedge from the back wall to the point $I$ in the topography is denoted as $L_{I}$. The second décollement (dashed line) is parallel to the first décollement at the distance $h$ from the accretion topography and has the properties $\left(\phi_{D}^{\prime}, C_{D}^{\prime}\right)$. Two collapse mechanisms of the type CM 2 defined in the section above could be proposed for an accretion layer thickness $H$ and $h$ and correspond solely to the activation of either lower or upper décollement. They both terminate at the front by thrusting to the free surface: points $F_{1}, G_{1}$, and $E_{1}$ and points $F_{\mathrm{u}}, G_{\mathrm{u}}$, and $E_{\mathrm{u}}$ in Figure $8(\mathrm{a})$, the subscripts 1 and $\mathrm{u}$ referring to the lower and upper décollement, respectively. The upper décollement activation mechanism is nevertheless not possible for an accretion layer of thickness $H$, since the whole wedge is compressed and the lower décollement has to be activated at least over a minimum section to ensure the transfer of activity to the upper décollement. This new mechanism is presented in Figure $8(\mathrm{~b})$ in the case where the transfer occurs close to the wedge front. The fault GF is again a shear plane separating the back stop (BS) from the lower hanging wall region $\left(\mathrm{HW}_{\mathrm{l}}\right)$. The ramp of this lower thrusting is however not cutting through the entire structure but stops as it reached the upper décollement at point $G^{\prime \prime}$. The sliding wall (SW) above the segment $G^{\prime \prime} G^{\prime}$ is gliding rigidly over the upper décollement. It is limited at its rear by the normal fault $G^{\prime \prime} F^{\prime \prime}$ which is also a shear plane. The point $G^{\prime}$ is the root of the two thrust faults $G^{\prime} F^{\prime}$ and $G^{\prime} E^{\prime}$ bounding the upper hanging wall $\left(\mathrm{HW}_{\mathrm{u}}\right)$ which defines the most frontal part of the thrusting mechanism. The application of the maximum strength theorem is rather systematic and 
provides the following expression for the upper bound to the force necessary to activate this new collapse mechanism

$$
\begin{aligned}
& Q_{\mathrm{u}}^{(7)} \cos \phi_{D}=\rho g\left(S_{B C} \sin \left(\phi_{D}+\beta\right)\right. \\
& \left.+\widehat{U}_{\mathrm{HW}} S_{\mathrm{HWl}} \sin \left(\theta_{\mathrm{G} G^{\prime \prime}}+\phi_{\mathrm{GE}}+\beta\right)\right)+\widehat{U}_{\mathrm{SW}} S_{\mathrm{SW}} \\
& \cdot \sin \left(\phi_{D}^{\prime}+\beta\right)+\widehat{U}_{\mathrm{HWu}} S_{\mathrm{HWu}} \sin \left(\theta_{G^{\prime} E^{\prime}}+\phi_{\mathrm{GE}}+\beta\right) \\
& +L_{A G} C_{D} \cos \phi_{D}+L_{G^{\prime} G^{\prime \prime}} C_{D}^{\prime} \cos \phi_{D}^{\prime}+C_{G E} \cos \phi_{G E} \\
& \cdot\left(L_{G G^{\prime \prime}} \widehat{U}_{\mathrm{HWl}}+L_{G^{\prime} E^{\prime}} \widehat{U}_{\mathrm{HWu}}\right)+C_{G F} \cos \phi_{G F} \\
& \cdot\left(L_{G F} \widehat{J}_{G F}+L_{G^{\prime \prime} F^{\prime \prime}} \widehat{J}_{G^{\prime \prime} F^{\prime \prime}}+L_{G^{\prime} F^{\prime}} \widehat{J}_{G^{\prime} F^{\prime}}\right),
\end{aligned}
$$

which is numbered seventh in our series. The two first lines correspond to the work of gravity, the third one to the resisting power of the two activated sections of the décollements, and the last two lines to the resisting power of the ramps and the shear planes. Note that all shear planes and ramps are assigned the friction properties $\left(\phi_{G F}, C_{G F}\right)$ and $\left(\phi_{G E}, C_{G E}\right)$, respectively, corresponding to the properties introduced for CM 2. The velocity norms in (11) are defined by

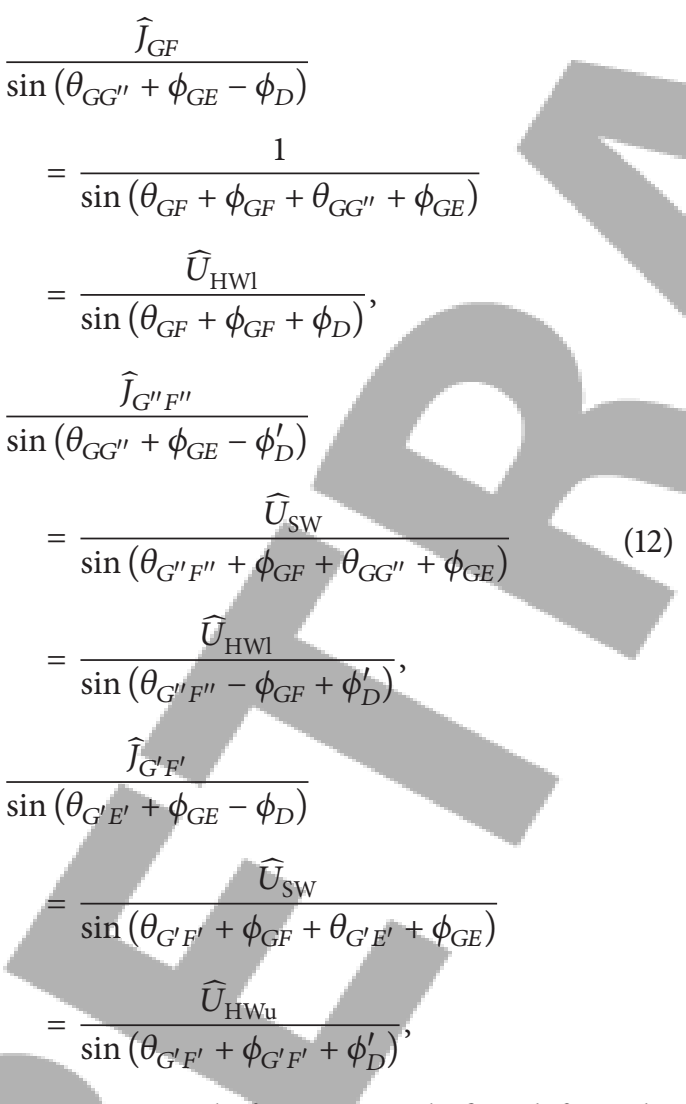

with the same notation as before; any angle $\theta_{X Y}$ defines the slope of the generic fault $X Y$.

The technical difficulty with this mechanism concerns the minimization of the upper bound in (11). There are three shear planes dips, two ramp dips, and the two lengths of the activated sections of the décollement which are unknown. These seven unknowns are equivalently replaced by the
TABLE 2: Geometrical and material properties for the study of the wedge with an accretion front. The missing information is found in Table 1 . The reference stress and length are still $\sigma_{R}=10 \mathrm{MPa}$ and $L_{R}=400 \mathrm{~m}$.

\begin{tabular}{llcc}
\hline Symbol & Definition & Value & Unit \\
\hline$\widetilde{L}_{I}$ & Length of triangle region & 100 & $\mathrm{~m}$ \\
$\widetilde{H}$ & Accretion layer thickness & 2.5 & $\mathrm{~m}$ \\
$\widetilde{h}$ & Depth of upper décollement & 1.25 & $\mathrm{~m}$ \\
$\phi_{D}$ & Lower décollement friction angle & 20 & $\mathrm{deg}$ \\
$\widetilde{C}_{D}$ & Lower décollement cohesion & 0.5 & $\mathrm{MPa}$ \\
$\phi_{D}^{\prime}$ & Upper décollement friction angle & 10 & $\mathrm{deg}$ \\
$\widetilde{C}_{D}^{\prime}$ & Upper décollement cohesion & 0 & $\mathrm{MPa}$ \\
\hline & & & \\
& & &
\end{tabular}

unknown positions of the seven points $F, F^{\prime \prime}, F^{\prime}, E^{\prime}, G, G^{\prime \prime}$, and $G^{\prime}$. The computation time required for optimization is of the order of $M N$, where $M$ is the number of points on the discretized surfaces and $N=7$ is the number of unknown points. Such calculation could be done advantageously on a GPU architecture or using linear procedures. A simplified approach is proposed in this contribution in the first attempt to gain some insight on this décollement transition. It is proposed that the selection of the frontal part of the thrusting mechanism (points $E^{\prime}, G^{\prime}$, and $F^{\prime}$ ) is independent of the four others and determined directly from the optimization of CM 2 proposed in Figure 8(a) for the upper décollement. The computation cost is then reduced to $M^{4}+M^{3}$ and is not an issue anymore. This proposition is not steered only by these technical difficulties only but by the observation that the upper thrusting part of CM 7 is identical to CM 2 with the only difference that the back stop velocity of CM 2 is now the velocity of the sliding wall. It is thus legitimate to assume that the optimum positions of points $E^{\prime}, G^{\prime}$, and $F^{\prime}$ could be obtained by isolating the frontal part of CM 7. The positions of $E^{\prime}, G^{\prime}$, and $F^{\prime}$ are thus taken as those of $E_{\mathrm{u}}, G_{\mathrm{u}}$, and $F_{\mathrm{u}}$ defined in Figure 8(a).

The first results constitute a comparison between CM 7 and CM 2 for the geometrical and material parameters provided in Table 2. The upper bound for the two mechanisms is provided in Figure 9(a) as a function of the topographic slope $\alpha$ of the triangle part of the wedge. The dotted-dashed curve for CM 2 is below the CM 7 curve for most of the range in values of $\alpha$ considered. There is however a window in the range between $6^{\circ}$ and $7.5^{\circ}$ for which the change in décollement can indeed occur. The inset within Figure 9 provides the position of the two collapse mechanisms for the slope of $6.5^{\circ}$ within this small interval. The transition from the lower to the upper décollement occurs at the rear of the wedge and the collapse mechanism (CM) 7 requires the main part of the upper décollement to be activated up to the thrust at the very front of the wedge. The ramps of CM 2 and the point $F^{\prime}$ of CM 7 are exactly at the breaking slope point $I$.

These results could be explained with the critical taper theory noting that $\alpha_{c}=6.36^{\circ}$ and $\alpha_{c}^{\prime}=2.10^{\circ}$ for the lower and the upper décollement, respectively. For that purpose, the $x_{1}$-coordinate of points $G^{\prime}, G^{\prime \prime}$, and $G_{1}$, normalized by the length $L_{I}$, have been plotted in Figure 9(b) as a function 


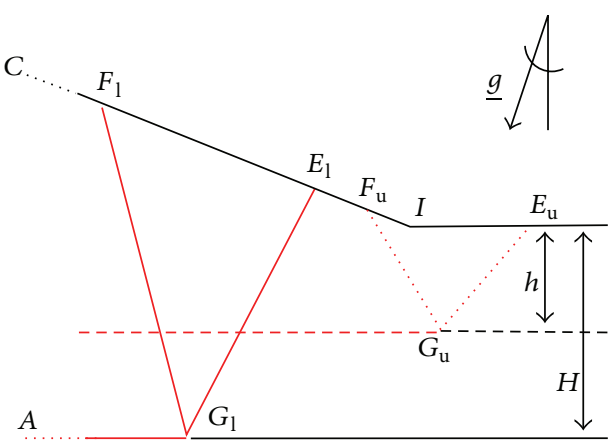

(a)

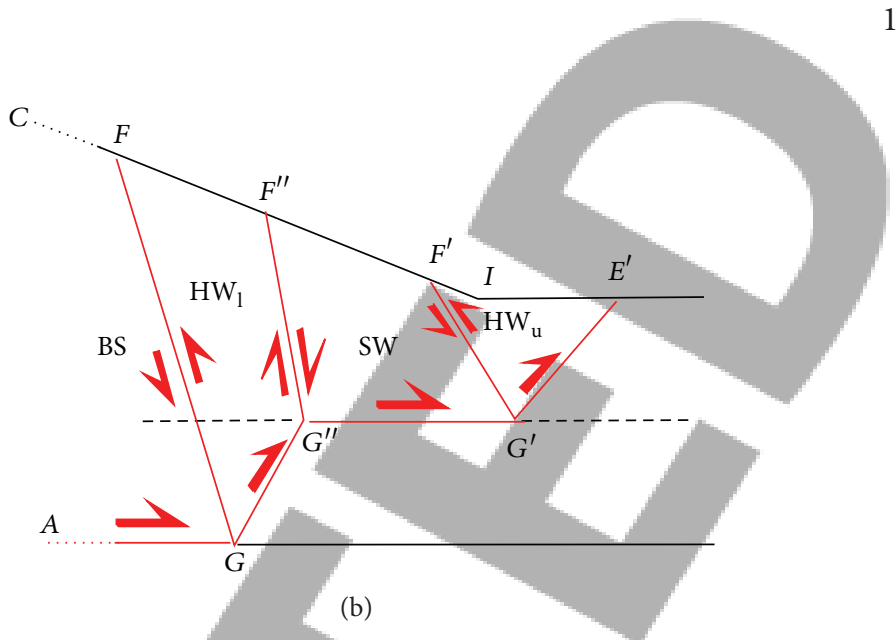

Figure 8: Two décollements are activated and could terminate with a thrusting to the free surface, (a). Mixed collapse mechanism number 7 includes a transition from the lower to the upper décollement and terminates with thrusting at the front (b).

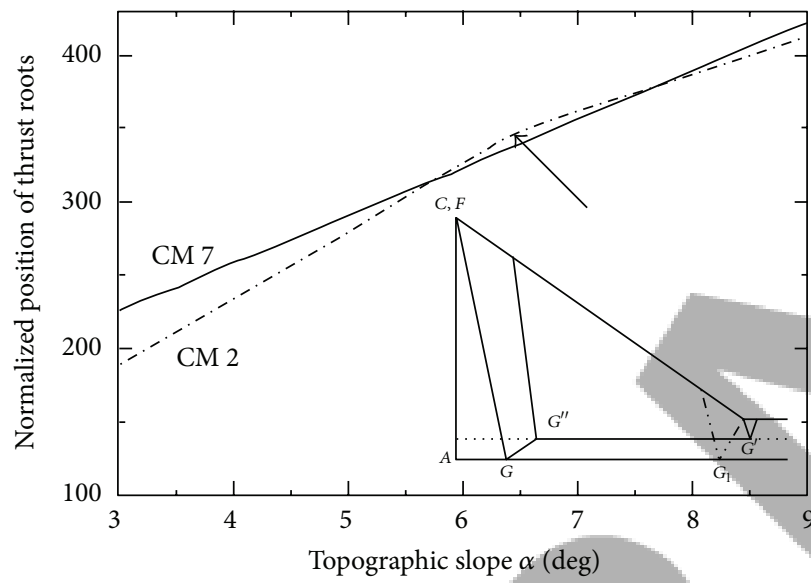

(a)

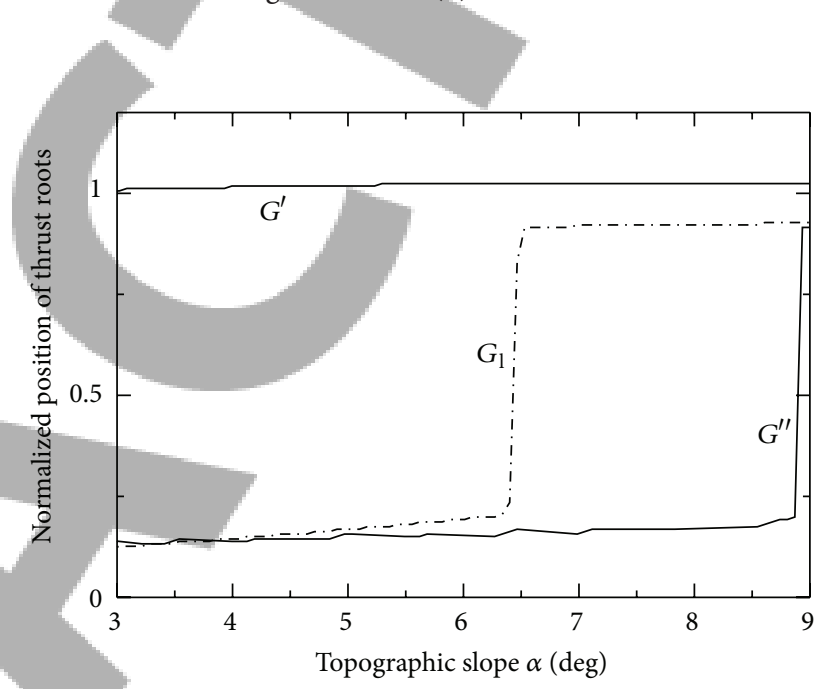

(b)

FIGURE 9: The bound for the change in décollement (CM 7) is compared to the bound for classical thrusting (CM 2), the two forces being a function of the topographic slope $\alpha$ (a). Note the small interval for dominance of CM 7. Note also in the inset, the transition occurs at the rear of the wedge in that interval. The positions of the three points $G, G^{\prime}$, and $G^{\prime \prime}$ are presented in (b) as a function of $\alpha$ to discuss stability conditions.

of the slope $\alpha$. The coordinate $G^{\prime}$ of the upper thrusting part of CM 7 is always greater than one since it is found on the accretion layer. This upper thrust is always supercritical since the values of $\alpha$ are exceeding $\alpha_{c}^{\prime}$. The choice of a zero cohesion is certainly responsible for the activation of the upper décollement beyond the point $I$. Point $G_{1}$ is close to the back of the wedge for $\alpha<\alpha_{c}$ and migrates abruptly to the front as soon as $\alpha$ exceeds $\alpha_{c}$, as expected. It is around this change in position that CM 7 appears to be dominant. However, the position of point $G^{\prime \prime}$ signaling the transition to the upper décollement is at the back of the structure. One has to consider larger topographic slope around $\alpha=9^{\circ}$ for this point $G^{\prime \prime}$ to be found at the front of the accretion wedge. Note however that the length $G^{\prime \prime} G^{\prime}$ of the activated upper décollement section is then small. It is for reason that the change in décollement is not so beneficial and that the dominant mechanisms remain CM 2 for these large topographic slopes.
Our prototype is certainly too simple to explain the frontal position of CM 7 and its dominance over CM 2. Several reasons could be evoked to explain this result including a gradient in frictional properties. One could imagine a negative gradient in the frictional properties towards the front which would penalize the transition from the lower to the upper décollement at the rear of the wedge. One could also imagine that the transition ramp $G G^{\prime \prime}$ is not a new fault but an inherited structure reactivated in compression. Another explanation is that the shape of the wedge at the front is more complex and then idealized in our prototype on a length scale corresponding to the activated section $G^{\prime \prime} G^{\prime}$ of the upper décollement. To investigate this possibility, a trilinear wedge has been considered, as seen in Figure 10. The slope of the segment $K I$ is kept constant at $5^{\circ}$ to make sure that the upper thrusting part of CM 7 is at the very front. The slope of the rear part of the topography $C K$ is changed over a small interval around the $9^{\circ}$ which was found necessary to obtain a point 


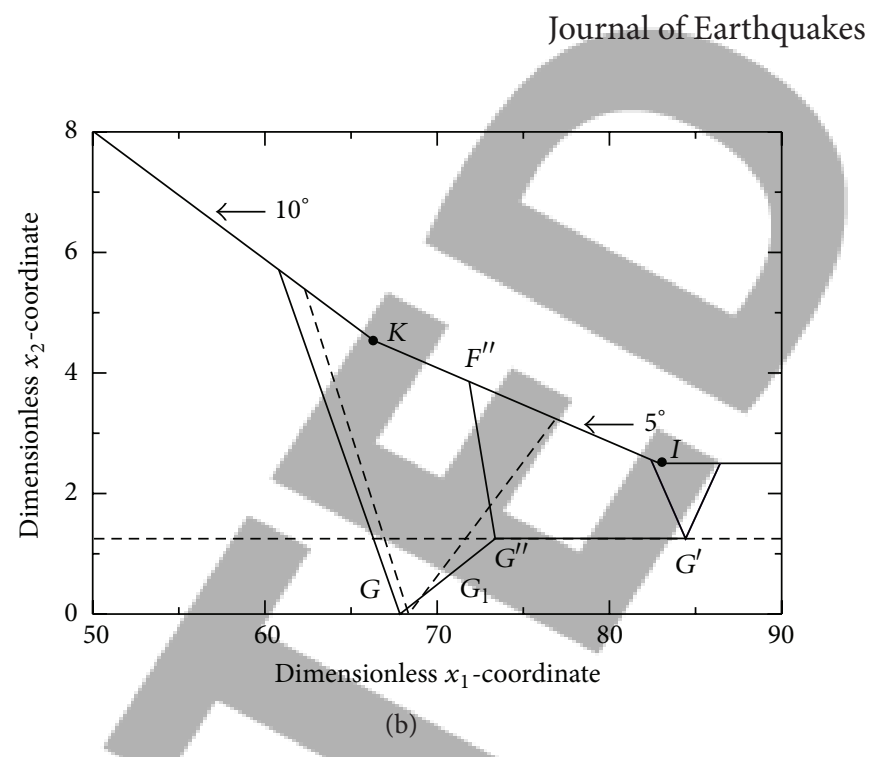

FIGURE 10: A bilinear topography prior to the accretion front is proposed to control the extent of the activated upper décollement for CM 7. The rear section dips at $8.9^{\circ}$ and $10^{\circ}$ in (a) and (b).

$G^{\prime \prime}$ at the front in our first set of results. The shapes of CM 7 and CM 2 are presented for $\alpha=8.9^{\circ}$ and $\alpha=10^{\circ}$ in solid and long dashed lines, respectively. For the slope of $8.9^{\circ}$, points $G$ and $G^{\prime \prime}$ are at the coordinates 62 and 68 on the lower and the upper décollement, respectively. The section of the upper décollement is activated in $G^{\prime \prime} G^{\prime}$ below the KI segment of the triangle region. The $\mathrm{V}$-shaped thrust of CM 2 is also presented in that figure for the same topography angle. The point $G_{l}$ is ahead of $G$ at the coordinate 67 so that CM 2 requires a longer activation of the lower décollement than CM 7. The results for $\alpha=10^{\circ}$ differ by the relative position of these two points: $G$ is now very close to $G_{1}$ and has shifted by a distance of 6 despite the small angular increase of $1.1^{\circ}$. Such large variation is typical at the critical stability conditions.

These preliminary results should be completed by a thorough parametric study but two results seem already to emerge. First, the change in décollement could dominate close to the criticality conditions for the wedge composed of the lower décollement $\left(\alpha_{c}\right)$. The transition from the lower to the upper décollement occurs at the back of the wedge at these critical conditions and to the front of the wedge for topographic slopes much larger (close to $1.5 \alpha_{c}$ for our parameters). Second, a curvature or a change in the topographic slope in the frontal region can provide the characteristic length controlling the extent of the activated section of the upper décollement.

\section{Delamination, Shear, and Compaction at Accretion Front}

This section concentrates on the search for the frontal mechanism setting aside the change in décollement depth just discussed. The prototype seen in Figure 11 has a single décollement at its base, and the objective is to study the deformation style at the accretion front. Four collapse mechanisms are considered and compared and the basic mechanism of CM 2 for which only frictional properties are required. The two delamination mechanisms CM 3 and CM
4 are also considered. The fourth mechanism is CM 5 which could explain the hinterland vergence of the triangle wedge (in Section 4) by introducing compaction. Note that CM 6 corresponding to the frontal vergence was not found of any interest and is not considered further here.

The velocity fields for these four collapse mechanisms are not different from the one discussed in Section 4 . The bound for CM 2 is still given by (2) and (3), the definitions for the back stop and the hanging wall remaining the same.

The velocity fields for CM 3 and CM 4 rely on a rotation around the point $R$ on the décollement and its position is a new unknown. The bounds to the tectonic force of $\mathrm{CM}$ 3 and CM 4 in the accretion wedge are similar to those in the triangle wedge, and the main difference is the account of compaction along the ligament $R E$. The application of the maximum strength theorem provides the two upper bounds presented as

$$
\begin{aligned}
& Q_{\mathrm{u}}^{(3)} \cos \phi_{D}=\rho g\left(S_{\mathrm{BS}} \sin \left(\phi_{D}+\beta\right)\right. \\
& \left.+\widehat{\omega}\left[\cos \beta\left(L_{A B} S_{\mathrm{HW}}-I_{1 \mathrm{HW}}\right)+\sin \beta I_{2 \mathrm{HW}}\right]\right) \\
& \quad+C_{D} L_{A G} \cos \phi_{D}+\widehat{\omega} T_{D} \frac{1}{2} L_{G B}^{2} \\
& \quad+C_{G F} L_{G F}\left(\widehat{J}_{G} \cos \phi_{G F}+\frac{1}{2} L_{G F} \widehat{\omega} \operatorname{cotan} \phi_{G F}\right) \\
& +\widehat{\omega}\left(\frac{1}{2} P_{R E}^{* 0} H^{2}-\frac{1}{6} G^{*} H^{3}\right),
\end{aligned}
$$

where $I_{1 \mathrm{HW}}$ and $I_{2 \mathrm{HW}}$ follow (4)

$$
\begin{aligned}
& Q_{\mathrm{u}}^{(4)} \cos \phi_{D}=\rho g\left(S_{\mathrm{BS}} \sin \left(\phi_{D}+\beta\right)\right. \\
& \left.+\widehat{\omega}\left[\cos \beta\left(L_{A B} S_{\mathrm{HW}}-I_{1 \mathrm{HW}}\right)+\sin \beta I_{2 \mathrm{HW}}\right]\right) \\
& \quad+C_{D} L_{A G} \cos \phi_{D}+\widehat{\omega} T_{D} \frac{1}{2} L_{G B}^{2} \\
& \quad+C_{G F} L_{G F} \int_{0}^{s_{F}} \widehat{J}_{G F}\left(s^{\prime}\right) d s^{\prime}+\widehat{\omega}\left(\frac{1}{2} P_{R E}^{* 0} H^{2}\right. \\
& \left.\quad-\frac{1}{6} G^{*} H^{3}\right),
\end{aligned}
$$

where $I_{1 \mathrm{HW}}$ and $I_{2 \mathrm{HW}}$ follow (6). 


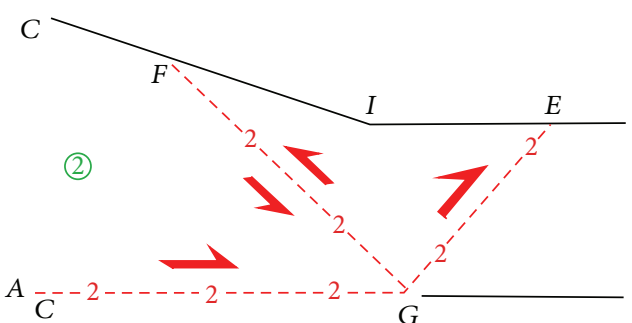

(a)

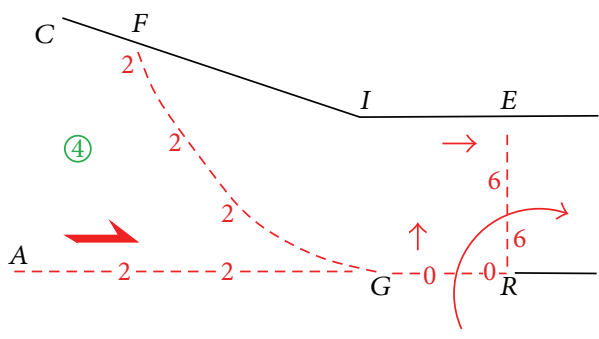

(c)
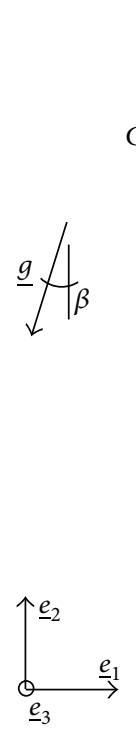

(3)

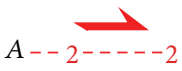

$------2$

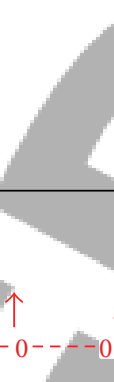

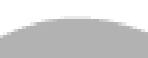
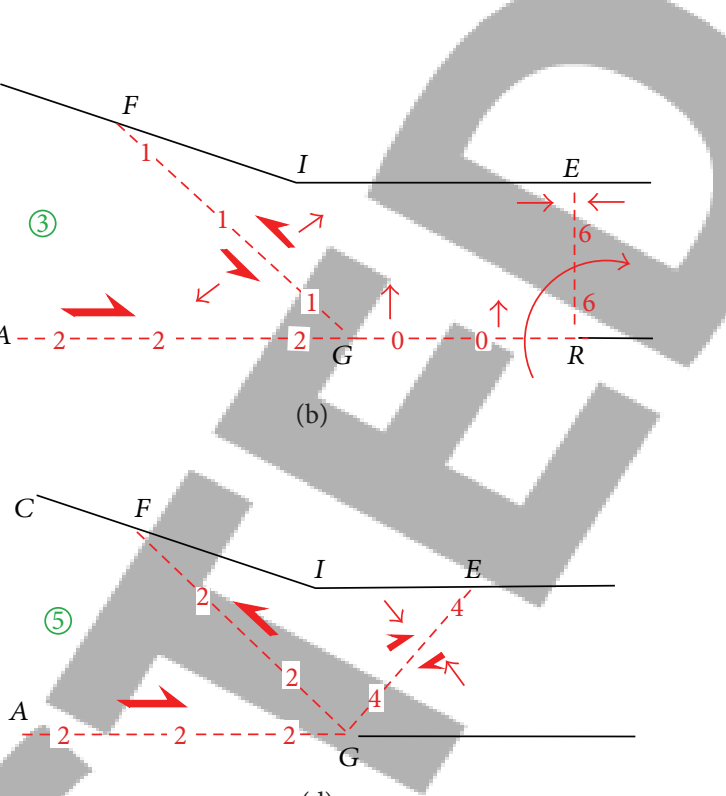

(d)

FIGURE 11: The four collapse mechanisms in competition at the front of accretion wedge.

The velocity field of CM 5 relies on compaction along its plane $G E$ to motivate the hinterland vergence. Moreover, a gradient in the compaction strength was considered in Section 4 to justify the position of this collapse mechanism. This gradient was proposed to be normal to the triangle wedge topography. It is found more convenient for this prototype which has an accretion front to assume that the gradient is perpendicular to the décollement. The expression for the bound to the tectonic force of CM 5 is still given by (8).

Geometrical and material parameters are presented in Table 3. The bounds for the four mechanisms of Figure 11 are presented in Figure 12(a) as a function of the topographic slope $\alpha$. All bounds, except CM 3 , are approximately bilinear. The bends in the curve signal the transition of the collapse mechanism from the rear towards the wedge front. Collapse mechanism 3, the delamination with a straight fault GF, is always at the front. The first mechanism to migrate to the front with increasing $\alpha$ is $C M 4$, the delamination with the curvy ramp. The next mechanism to migrate to the front is CM 2, the classical frictional faulting, and the last is the CM 5. It is this last mechanism which dominates for the set of parameters proposed here. Note that the difference between CM 2, 4, and 5 is rather small once these three mechanisms are at the front. This difference is less than $2.5 \%$ and it decreases with decreasing $\widetilde{H}$. Moreover, it was found that CM 2 became dominant once $\widetilde{H}$ is set to less than 1 .

In view of the small differences between the various bounds, imperfections could thus play an essential role in selecting the dominant mechanisms for thin accretion layers. For example, assuming the curvy fault GF of CM 4 to have a reduced frictional angle of $20^{\circ}$ instead of $30^{\circ}$ is enough to reduce the corresponding bound and thus for this CM 4 to become dominant. Changing the cohesion of the

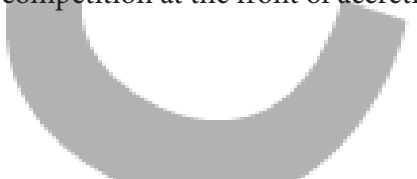

TABLE 3: Geometrical and material properties for the wedge with an accretion layer and the four collapse mechanisms presented in Figure 11. Information unchanged compared to Section 4 is provided in Table 1 . The reference stress and length are still $\sigma_{R}=10 \mathrm{MPa}$ and $L_{R}=400 \mathrm{~m}$.

\begin{tabular}{llcc}
\hline Symbol & Definition & Value & Unit \\
\hline$\widetilde{L}_{I}$ & Length of triangle region & 0 & $\mathrm{~m}$ \\
$\widetilde{H}$ & Accretion layer thickness & 2.5 & $\mathrm{~m}$ \\
$\phi$ & Bulk friction angle & 30 & $\mathrm{deg}$ \\
$\phi^{*}$ & Bulk compaction angle & 40 & $\mathrm{deg}$ \\
$\widetilde{C}$ & Bulk cohesion & 1 & $\mathrm{MPa}$ \\
$\widetilde{P}^{* 0}$ & Bulk compaction strength at surface & 5 & $\mathrm{MPa}$ \\
$\widetilde{G}^{*}$ & Bulk compaction strength gradient & 2.5 & \\
$\phi_{D}$ & Décollement friction angle & 10 & $\mathrm{deg}$ \\
$\widetilde{C}_{D}$ & Décollement cohesion & 0.5 & $\mathrm{MPa}$ \\
$\widetilde{T}_{D}$ & Décollement tensile strength & 0 & $\mathrm{MPa}$ \\
\hline
\end{tabular}

décollement, however, does not change the dominance of CM 5 for thicker accretion layers.

The positions of the collapse mechanisms are sensitive to the topographic slope $\alpha$ and they are presented in Figure 12(b) for the specific slope $\alpha=4.5^{\circ}$. CM 2 (solid lines) and CM 5 (dotted-dashed) are in the same region with faults $G F$ subparallel. The fault $G E$ of the compacting mechanism is however steeper and, consequently, the surface of the hanging wall is smaller than the one needed for CM 2, explaining certainly the dominance of CM 5. The two delamination mechanisms are more to the front with a longer delamination segment for CM 3 compared to CM 4. The consequence is again due to gravity forces: the surface of the accretion layer 


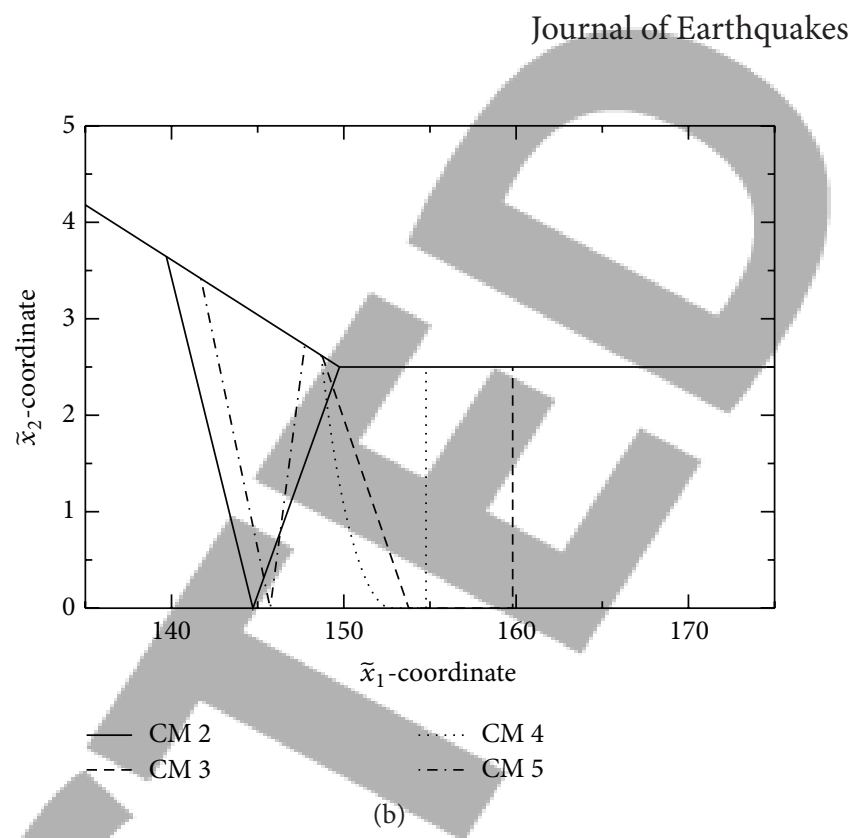

(a)

FIgURE 12: The bounds for the four CM defined in Figure 11 as a function of the topographic slope $\alpha$ (a). The positions of these collapse mechanism are presented in (b) for $\alpha=4.5^{\circ}$.

lifted by delamination is larger for CM 3 than for CM 4, explaining the advantage of the latter mechanism.

\section{Discussion}

By analyzing their virtual velocity fields and comparing their least upper bounds, five collapse mechanisms are investigated in the competition for the initiation of triangle zones in triangle and accretion wedges.

By comparing the predictions of collapse mechanism numbers 1 and 2 with the critical taper theory, a good agreement is achieved between the limit analysis (supporting this research) and the classical taper theory for cohesionless wedges. In a triangle wedge the position of the thrust fault cannot be anywhere by following the rule of either subcritical or super-critical condition predicted by the classical taper theory. Results from a series of tests indicate that the stability of the cohesive triangle wedges is controlled by three factors: the length of the basal décollement, the cohesion of the bulk, and the décollement. This finding is consistent with the previous findings $[10,12]$. Couzens-Schultz et al. [12] suggested that the strength of the décollements of the rock layers plays a significant role in controlling the style of duplex. The frictional characteristics of the upper and lower detachments have influence not only on the initiation of triangle zone, but also on the distribution of deformation in an evolving triangle zone [10].

Delamination mechanism numbers 3 and 4 always emerge at the front of the triangle wedge by following supercritical rule, so that mechanism number 2 dominates in the competition with mechanisms 3 and 4 . The reason could be attributed to the gravity force of the hanging wall, since the external power consumed in the rotation of the whole hanging wall in mechanism numbers 3 and 4 is much larger than that in mechanism number 2 . This result suggests that delamination prefers to occur in shallow sediment where there is lower density than in deep crust. This finding is supported by the observation from Bossort [20] that the density of shallow section above the triangle zone is significantly lower than that of the underlying thrust-faulted sequence in southern Alberta. If mechanism number 3 dominates in a shallow and lower density sediment, it supports that upward decease of density across the back thrust favors uplifting the overlying section rather than up thrusting the denser underlying sheets to the surface. The denser thrust sheet could keep flat at the décollement level to wedge and uplift the overlying lower density material upward with rotation. This investigation is also supported by the observations that triangle zones commonly develop at mountain fronts where it prefers to occurr at shallow levels in young sediments [21]. Couzens and Wiltschko [9] suggested that triangle zones may form in the late stages of thrust belt evolution, when significant synorogenic deposits accumulated at the deformation front by reconstructing the frontal stratigraphy of the Wyoming thrust belt. The triangle zone observed in the Longmen Shan fold-and-thrust best emerges at the depth less than $5 \mathrm{~km}$ in the Trias sediment of the Longmen Shan foothill and the adjacent Sichuan Basin [2-4]. In order to discover the details of how the density and thickness of the frontal sediment are playing the role in the competition of different mechanism, thorough parameterization tests should be conducted in the future.

However, a weak (softening) back thrust introduced in mechanism numbers 3 and 4 improves the situation of delamination mechanisms in the competition. Mechanism number 3 begins to dominate by delaminating along the horizontal décollement and shear along the thrust in the triangle wedge. The reason could be attributed to the decreasing of the inner power consumed on the activation along the back thrust. 
In a triangle wedge mechanism numbers 5 and 6 of the combination of shear-enhanced compaction and Coulomb shear consume less power than mechanism number 2 of Coulomb shear. Moreover, the hinterland thrust (mechanism number 5) is preferred to the foreland thrust (mechanism number 6) in competition of the two compaction mechanisms. However the advantage is slight in the compaction by mechanism number 5 over riding mechanism numbers 6 and 2. Mechanism number 5 also dominates in the accretion wedge with a thick toe accretion wedge, while mechanism number 2 dominates in a thin toe accretion wedge.

In an accretion wedge mechanism number 5 loses the advantage and mechanism number 4 becomes dominant with decreasing the frictional angle of back thrust. This finding agrees with the previous proposal [7] that the frictional characteristics (friction angle) of the thrust have influence on the distribution of deformation in an evolving triangle zone. Collapse mechanism number 5 of Coulomb shear on the back thrust and shear-enhanced compaction on the ramp is a new introduction for a possible collapse mechanism in the accretion wedge.

The collapse mechanism in the two décollement accretion wedges is also investigated. The results indicate the change of the décollement by a ramp (fore thrust) from the lower flat décollement to the upper décollement happens. However, this changing is depending on the wedge conditions. It occurs either at the rear on the critical condition of the lower décollement or at the front of the wedge with the large topography. The topography of the fold-and-thrust belts of mountain front is always much more complicated than our proposed bilinear and trilinear prototypes in this research. The real topography with changing slops plays a significant role in the activation of the length of the lower and upper décollement and the position of the ramp which connects the two décollements. High topography activates the changing décollement near the front of the wedge by mechanism number 4 with curvy fault. This suggests that erosional process which shapes the morphology of mountain front is important in the formation of triangle zones. By conducting analogue models Montanari et al. [14] proposed that the syntectonic erosion that promotes the development of passive-roof duplex style is one of the major roles in the formation of triangle zone at Vena del Gesso Basin (Romagna Apennines, Italy). The Longmen Shan range locates in the south Asian monsoon zones indicating high incision rate in this region. During the topography building process the morphology of the Longmen Shan has been shaping by heavy erosion together with the large scale land slide induced by repeating large earthquake like the 2008 Mw7.9 Wenchuan earthquake [22]. The formation of the triangle zone at the termination of the Longmen Shan fold-and-thrust belt may be influenced by the changing slope during the mountain building process.

\section{Conclusions}

Five collapse mechanisms by delamination, shear, and compaction are introduced to the competition in the formation of triangle zone front of fold-and-thrust belts as follows. The first mechanism is the classical Coulomb shear thrust. The second is delamination at the frontal part of the décollement with straight back thrust, while the third is delamination with curvy back thrust. The forth is the combination of ramp with Coulomb shear and shear-enhanced compact fault, while the fifth is the combination of the exchanging motion on the ramp and thrust. The dominating mechanism in the formation of triangle zones relies on the competition of the least upper bound of each mechanism when subjected to tectonic force. The controlling factors of the competition are discovered and summarized as follows: (1) the frictional characters and cohesion of horizontal décollements and thrust, (2) the slope of the topography of accretion wedge, and (3) the thickness and the rock density of the front toe of accretion wedge.

\section{Appendices}

This section presents the details of the derivation of the upper bounds presented in the main text. The structure of those appendices follows exactly the one of the main text except for the first section which is devoted to the definition of the support function.

\section{A. Material Strength and Support Function}

Central to the maximum strength theorem used throughout this contribution is the bounding of the power done on any discontinuity. It is the support function which defines this maximum power and it is directly related to the material strength, as it is discussed in this section.

Consider a material which is cohesive, frictional, compactant, and dilatant. An arbitrary plane is crossing this material and is oriented by the normal vector $n$, pointing to the positive side + and the tangent vector $t$ in this $2 \mathrm{D}$ setting (Figure 13(a)). The stress vector acting on this plane is $\underline{T}$ and is decomposed in a normal $\sigma_{n}$ and a tangential component $\tau$ in the right-handed basis $\{n, t\}$. Failure occurs if the stress vector reaches the boundary of the strength domain presented in the same figure. This boundary is characterized by three scalars having dimension of stress, $P^{*}, C$, and $T$ corresponding to the maximum compressive strength (positive), the cohesion, and the tensile strength (not to be confused with the stress vector), respectively. Two angles are also necessary, the classical Coulomb frictional angle $\phi$ and the compaction angle $\phi^{*}$, orienting the two segments closing the strength domain in compression. Note that this general strength domain is convex in the $\left(\sigma_{n}, \tau\right)$ space.

The failure plane considered accommodates a velocity discontinuity $\widehat{\underline{J}}$ defined as the difference between the velocity vectors on the positive and the negative side $\left(\widehat{J}=\widehat{U}^{+}-\widehat{U}^{-}\right)$. The superposed hat on the velocities is to remind the reader that any velocity, consistent with boundary conditions, could be considered and not just the exact, unknown velocity. Any such velocity field is said to be kinematically admissible (KA). The power at any point on the plane is the scalar product $\underline{T} \cdot \widehat{J}$ between the unknown stress vector and the velocity jump $\widehat{J}$. The maximum power is defined by the support function, 


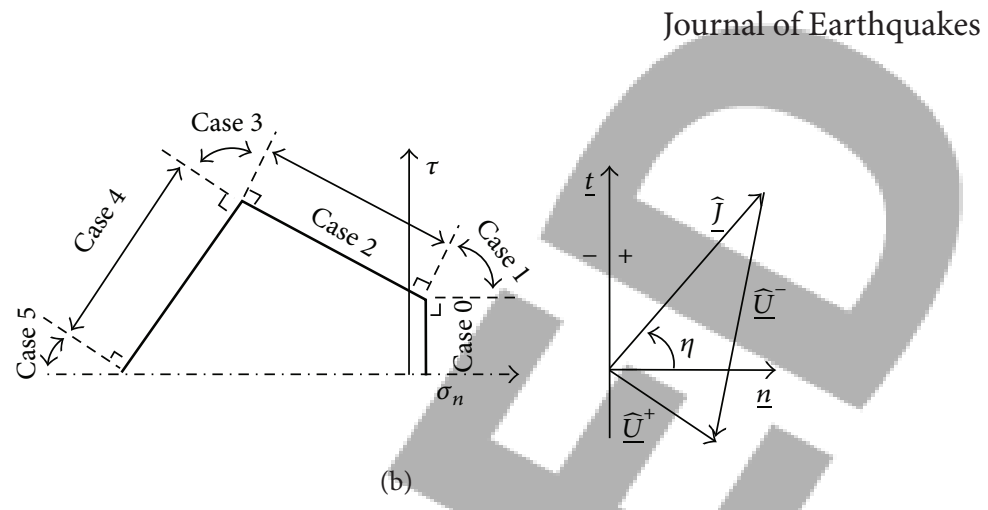

(a)

FIGURE 13: The general strength domain for a frictional, cohesive, compactant, and dilatant material is characterized by the friction angle $\phi$, the compaction angle $\phi^{*}$, the cohesion $C$, the tensile strength $T$, and the maximum compressive strength $P^{*}$ (a). The support function $\pi(\widehat{J})$ is defined in terms of the orientation of the velocity jump vector $\widehat{J}$, the angle $\eta$ measured anticlockwise from the normal to the interface. The values of $\pi(\widehat{J})$ are defined in (13) for the six orientation cases presented in (b).

constructed by a graphical method [16], and it reads for the general strength domain

case $0: \quad \eta=0$,

$$
\pi(\underline{J})=\widehat{J} T,
$$

case $1: \quad 0<\eta<\frac{\pi}{2}-\phi$,

$$
\pi(\widehat{J})=\widehat{J}\left[\frac{\cos (\eta+\phi)}{\cos (\phi)} T+C \sin (\phi)\right],
$$

case $2: \quad \eta=\frac{\pi}{2}-\phi$,

$$
\pi(\widehat{J})=\widehat{J} C \cos (\phi),
$$

case $3: \quad \frac{\pi}{2}-\phi<\eta<\frac{\pi}{2}+\phi$,

$$
\pi(\underline{J})=\widehat{J} C \cos (\eta) \bar{\delta}+\sin (\eta) \bar{\tau},
$$

case $4: \quad \eta=\frac{\pi}{2}+\phi^{*}$

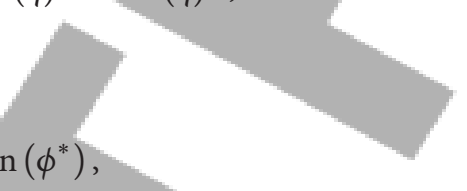

case $5: \frac{\pi}{2}+\phi^{*}<\eta<\pi$,

$$
\pi(\widehat{J})=\widehat{J} P^{*} \cos (\eta),
$$

(A.1)

in which the two scalars introduced for case 3 are

$$
\begin{aligned}
\bar{\delta} & =\frac{C-P^{*} \tan \phi^{*}}{\tan \phi+\tan \phi^{*}}, \\
\bar{\tau} & =\frac{\left(C+P^{*} \tan \phi\right) \tan \phi^{*}}{\tan \phi+\tan \phi^{*}} .
\end{aligned}
$$

They correspond to the intersection of the Coulomb line and the compaction truncation line presented in Figure 13(a). The support function in (A.1) is defined in five cases, corresponding to different values or ranges of the orientation angle $\eta$, and presented in Figure 13(b). Note that the range of $\eta$ between $\pi$ and $2 \pi$ is also partitioned in five cases, completely symmetric to the one illustrated here.

This general strength domain summarizes all the properties which could be of interest in this contribution but they are not all assigned to a given material. In fact, the bulk material is considered to be frictional, cohesive, and compactant so that its tensile strength is set by the Coulomb intersection with the $\sigma_{n}$ axis to $C \operatorname{cotan} \phi$. The décollement is cohesive, frictional, and compactant but its compressive strength is infinite leading to an unbounded strength domain. Cases 3 to 5 in (A.1) are associated with an infinite support function. These three cases are of no interest and their angular ranges will be avoided. These differences between the bulk and the décollement properties are illustrated in Figure 14.

\section{B. Triangle Wedge}

B.1. Mechanism Numbers 1 and 2. Collapse mechanism number 1 is the simplest and should be dominant for super-critical slopes if only friction prevails. It consists of the gliding of the whole wedge on the décollement. This mechanism is now used to illustrate the application of the maximum strength theorem.

The virtual velocity of the wedge is of unit norm and oriented at $\phi_{D}$ from the décollement in the orthonormal basis illustrated in Figure 15. This vector orientation corresponds to case 2 of the support function associated with the décollement. The external forces include the gravity force $\left(-\rho g \underline{e}_{2}\right)$, where $\rho$ and $g$ are the material density and the acceleration, respectively, as well as the tectonic force of magnitude $Q$ applied on the back wall $A C$, in a direction parallel to the décollement. The external power is the power of these forces over the velocity field and reads $\left(-\rho g \sin \left(\phi_{D}+\right.\right.$ $\left.\beta) S_{A B C}+Q \cos \left(\phi_{D}\right)\right)$, where $S_{A B C}$ is the surface of the wedge. This power will be compared to the maximum resisting power which is the sum of support function over the dissipative discontinuities, here the décollement. This power in case 2 is thus $C_{D} \cos \phi_{D} L_{A B}$. The maximum strength theorem stipulates that the external power is always smaller than the maximum resisting power providing an upper bound to the applied force presented in (1) in the main text. 


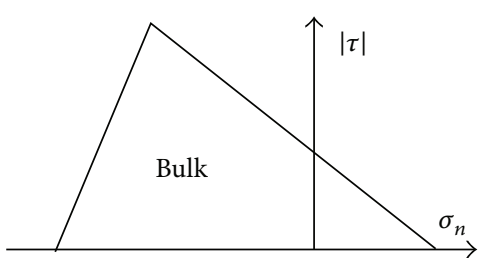

(a)

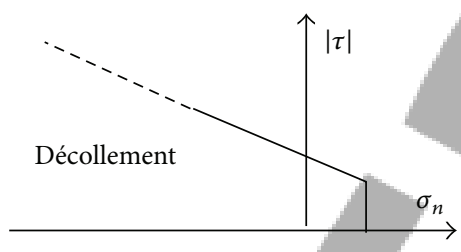

(b)

FIGURE 14: The bulk material is frictional, cohesive, and compactant. Its tensile strength is set by the Coulomb line (a). The décollement is frictional and dilatant. Its compressive strength is infinite (b).

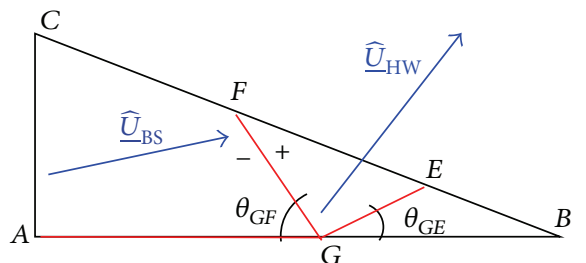

(a)

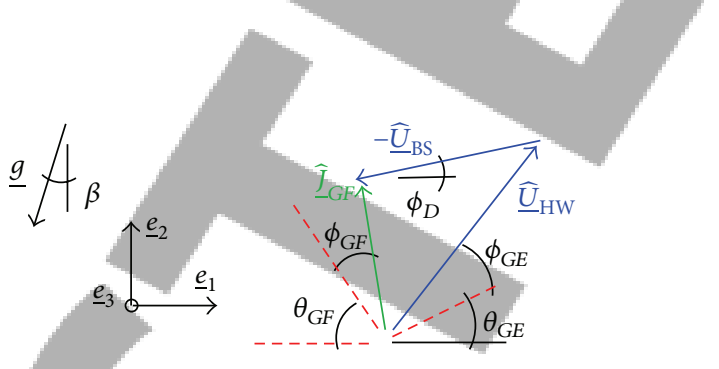

(b)

Figure 15: Collapse mechanism number 2 consists of a thrust fold with the partial activation of the décollement from the backwall to the common root of the two faults on the décollement.

The technical difficulties start with mechanism number 2 for which collapse occurs by a thrust fold which decomposes the wedge into three regions, the toe $(G B E)$, the hanging wall $(G F E)$, and the back stop (ACFG), respectively (Figure 15(a)). This mechanism has been studied by Cubas et al. [19] and the derivation of the upper bound is repeated here for sake of completeness.

The virtual velocity field is as follows. The back stop region has the velocity $\widehat{U}_{\mathrm{BS}}$ which is a unit vector oriented at the angle $\phi_{D}$ from the décollement, as for mechanism number 1. The hanging wall velocity is $\widehat{\underline{U}}_{\mathrm{HW}}$ and oriented at $\phi_{G E}$ from the fault $G E$. The jump over the fault $G F$ is the difference $\widehat{J}_{G F}=\widehat{U}_{H W}-\widehat{U}_{B S}$, a vector which is oriented at $\phi_{G F}$ with respect to the fault GF. The norm of this jump and the norm of the hanging wall velocity are obtained by application of the law of sine to the hodogram presented in Figure 15(b):

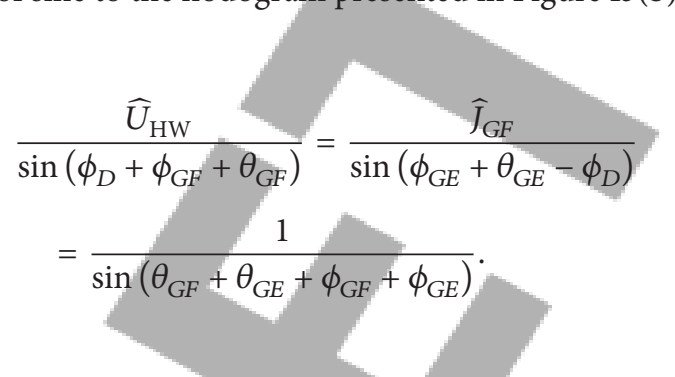

The validity of this construction relies on the following constraints over the friction angles and dips:

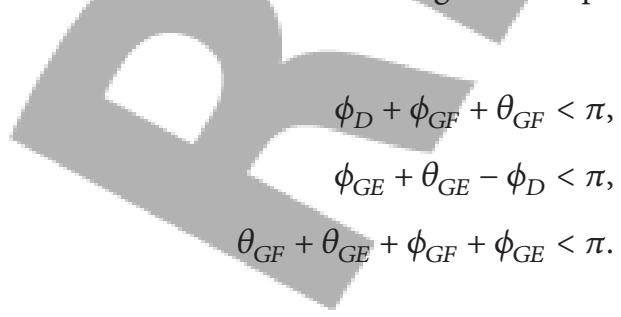

The external work associated with this velocity field reads

$$
\begin{gathered}
P_{\text {ext }}(\widehat{U})=Q \cos \phi_{D}-\rho g\left(S_{B C} \sin \left(\phi_{D}+\beta\right)\right. \\
\left.+\widehat{U}_{H W} S_{H W} \sin \left(\phi_{G E}+\theta_{G E}+\beta\right)\right)
\end{gathered}
$$

in which $S_{\mathrm{BS}}$ and $S_{\mathrm{HW}}$ are the surface of the back stop and of the hanging wall, respectively. The maximum resisting power corresponds to the sum of the support function over every discontinuity. The support function is always in case 2 (A.1), the basic assumption considered to build the virtual velocity field. This power reads

$$
\begin{aligned}
P_{\mathrm{mr}}(\widehat{\widehat{U}})= & L_{A G} C_{D} \cos \phi_{D}+C_{G F} L_{G F} \widehat{J}_{G F} \cos \phi_{G F} \\
& +C_{G E} L_{G E} \widehat{U}_{\mathrm{HW}} \cos \phi_{G E} .
\end{aligned}
$$

The application of the maximum strength theorem for this second mechanism which stipulates that $P_{\text {ext }} \leq P_{\mathrm{mr}}$ for any KA velocity field results in the upper bound in the applied force which is provided in the main text as (2).

B.2. Mechanism Number 3: Delamination of the Frontal Part of the Décollement. The wedge is partitioned into two regions for mechanism number 3. The frontal part GFB is called the hanging wall and the rest is the back stop (Figure 16(a)). The velocity field of the back stop is the same as for the two previous mechanisms. The hanging wall sustains a rotation $-\widehat{\omega} \underline{e}_{3}$ around point $B$ such that the velocity at any point positioned by the vector $\underline{x}$ is $-\widehat{\omega} \underline{e}_{3} \wedge\left(\underline{x}-\underline{x}_{B}\right)$. The velocity jump at point $G$ on the décollement is $\widehat{J}_{G}=\widehat{\omega} L_{G B} \underline{e}_{2}-\widehat{U}_{G F}$.

The hodogram of this velocity difference is presented in Figure 16(b) in which the jump is oriented according to case 2 of the support function. For the velocity of the back stop 


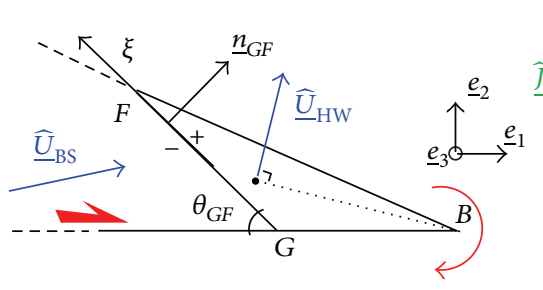

(a)

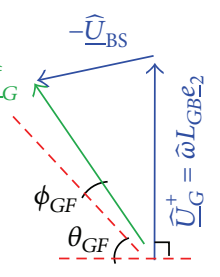

(b)
FIGURE 16: The virtual velocity field for collapse mechanism number 3 and the hodogram of the velocity jump at point $G$.

being fully determined, the virtual angular velocity is found by application of the law of sines to this hodogram

$$
\frac{\widehat{\omega} L_{G B}}{\sin \left(\phi_{D}+\phi_{G F}+\theta_{G F}\right)}=\frac{1}{\cos \left(\phi_{G F}+\theta_{G F}\right)}=\frac{\widehat{J}_{G}}{\cos \phi_{D}},
$$

which provides also the magnitude of the velocity jump at point $G$. The velocity along the fault $G F$ on the hanging wall side is expressed as $\widehat{U}_{G}^{+}+\xi \underline{n}_{G F}$ where the $\xi$-axis, parallel to the fault, originates at point $G$ and $\underline{n}_{G F}$ is the normal vector (Figure 16(a)). The jump over the fault $\widehat{J}_{G F}$ is thus the sum $\widehat{J}_{G}+$ $\xi_{n_{G F}}$, a vector which is oriented in the cone corresponding to case 1 of the support function, regardless of the orientation $\theta_{G F}$ of the fault.

The power of the external work has three contributions, the first being due to the tectonic force $Q \cos \phi_{D}$ and the second to the work of gravity on the back stop $\sin \left(\phi_{D}+\right.$ $\beta) \rho g S_{\mathrm{BS}}$. The third contribution is the sum of the product

$$
-\rho g\left(\sin \beta \underline{e}_{1}+\cos \beta \underline{e}_{2}\right) \cdot\left(-\widehat{\omega} \underline{e}_{3}\right) \wedge\left(\underline{x}-\underline{x}_{B}\right)
$$

over the hanging wall. This product could be rewritten in terms of the classical triple product

$$
\rho g \widehat{\omega}\left\{\sin \beta\left[\underline{e}_{1}, \underline{e}_{3}, \underline{x}-\underline{x}_{B}\right]+\cos \beta\left[\underline{e}_{2}, \underline{e}_{3}, \underline{x}-\underline{x}_{B}\right]\right\},
$$

which is simplified to

$$
\begin{aligned}
\rho g \widehat{\omega} & \left\{\sin \beta\left[\underline{e}_{1}, \underline{e}_{3}, x_{2} \underline{e}_{2}\right]\right. \\
+ & \left.\cos \beta\left[\underline{e}_{2}, \underline{e}_{3},\left(x_{1}-x_{1 B}\right) \underline{e}_{1}\right]\right\},
\end{aligned}
$$

because of the trilinearity and the orthogonality properties. The resulting scalar is

$$
\rho g \widehat{\omega}\left\{-\sin \beta x_{2}+\cos \beta\left(x_{1}-x_{1 B}\right)\right\}
$$

which has to be integrated over the hanging wall. The end result is

$$
\rho g \widehat{\omega}\left[\cos \beta\left(L_{A B} S_{\mathrm{HW}}-I_{1 \mathrm{HW}}\right)+\sin \beta I_{2 \mathrm{HW}}\right],
$$

where the moments $I_{1 \mathrm{HW}}$ and $I_{2 \mathrm{HW}}$ are defined in the main text with (4). In summary, the total external power reads

$$
\begin{aligned}
& P_{\text {ext }}(\underline{\widehat{U}})=Q \cos \phi_{D}-\rho g\left(S_{B C} \sin \left(\phi_{D}+\beta\right)\right. \\
& \left.\quad+\widehat{\omega}\left[\cos \beta\left(L_{A B} S_{\mathrm{HW}}-I_{1 \mathrm{HW}}\right)+\sin \beta I_{1 \mathrm{HW}}\right]\right) .
\end{aligned}
$$

The maximum resisting power is the sum of the support function over the dissipative surfaces, the décollement, and the fault GF. The dissipation over the section $A G$ of the décollement is, as for the other mechanisms, $C_{D} \cos \phi_{D} L_{A G}$ and the opening of section $G B$ provides $\widehat{\omega} T_{D} 1 / 2 L_{G B}$, since the velocity jump is oriented according to case 0 of the support function. The dissipation over the fault $G F$ is the sum of the support function defined by the product

$$
C_{G F} \operatorname{cotan} \phi_{G F} \underline{n} \cdot\left(\widehat{J}_{G}+\xi \widehat{\omega}_{\underline{G F}}\right),
$$

at any point along the $\xi$-axis. This sum is calculated noting that the velocity jump at $G$ is oriented according to case 2 $\left(\underline{n} \cdot \widehat{J}_{G}=\cos \phi_{G F} \widehat{J}_{G}\right)$, and the total, maximum resisting power reads

$$
\begin{aligned}
& P_{\mathrm{mr}}(\underline{\widehat{U}}) \\
& =L_{A G} C_{D} \cos \phi_{D}+\widehat{\omega} T_{D} \frac{1}{2} L_{G B}^{2} \\
& \quad+C_{G F}\left(\cos \phi_{G F} \widehat{J}_{G} L_{G F}+\widehat{\omega} L_{G F}^{2} \frac{1}{2} \operatorname{cotan} \phi_{G F}\right) .
\end{aligned}
$$

Application of the maximum strength theorem then results in the expression for the upper bound found in (4) in the main text.

B.3. Mechanism Number 4: Delamination with a Curved Fault. The main difficulty with this mechanism is the determination of the locus of the curved fault GF parameterized by the arc length $s$ with origin at point $G$ (Figure 17(a)). The boundary condition at point $G$ is that the curve is tangent to the decollement so $\theta_{G F}(s=0)=0, \underline{t}(s=0)=-\underline{e}_{1}$, and $\underline{n}(s)=\underline{e}_{2}$, these quantities being defined at arbitrary $s$ in Figure 17(a). The curve GF is constructed with the following second-order asymptotic development in increment $\Delta s$ :

$$
\underline{x}(s+\Delta s)=\underline{x}(s)+\Delta s \underline{t}(s)+\frac{\Delta s^{2}}{2} \kappa(s) \underline{n}(s),
$$

having introduced the Serret-Frenet relations and $\kappa$ defining the curvature found from

$$
\kappa(s)=\underline{n}(s)+\frac{d}{d s} \underline{t}(s)=\frac{d}{d s} \theta_{G F}(s) .
$$

Consider now an arbitrary point $M$ on the fault GF of coordinates $\left(x_{1}, x_{2}\right)$ and arc length $s$. The velocity on the plus side of point $M, \widehat{U}^{+}(s)$ is perpendicular to the segment $M B$ and the velocity jump reads

$$
\begin{aligned}
\widehat{J}_{G F}(s)= & \left(\widehat{\omega} x_{2}-\cos \phi_{D}\right) \underline{e}_{1} \\
& +\left(L_{A B}-x_{1}-\sin \phi_{D}\right) \underline{e}_{2} .
\end{aligned}
$$

At the origin, this jump is the vector $\widehat{J}_{G}$ which is the difference $\widehat{\omega} L_{G B} \underline{e}_{2}-\widehat{U}_{\mathrm{BS}}$. The hodogram of this velocity jump is presented in Figure 17(b) and the virtual rotation rate $\widehat{\omega}$ is 


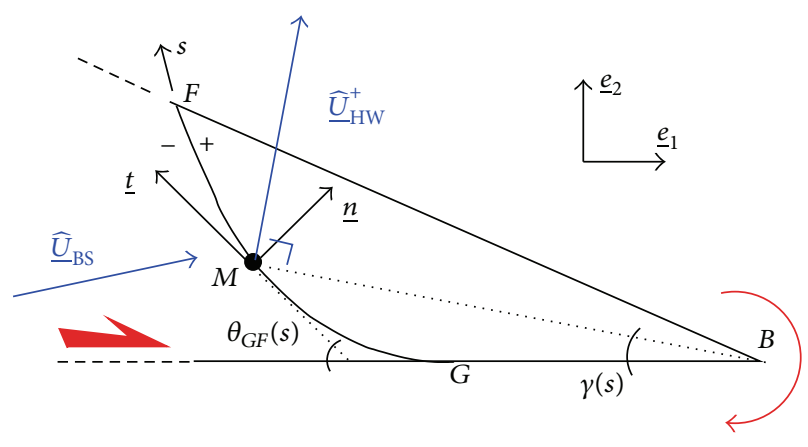

(a)

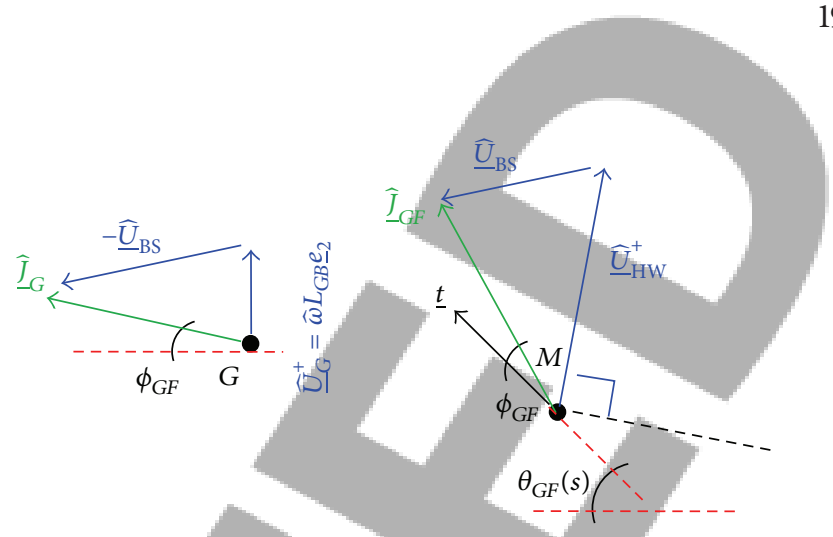

(b)

FIGURE 17: The virtual velocity field for collapse mechanism number 4 and the hodograms of the velocity jump at point $G$ and any point $M$ on the curved fault.

chosen such that the velocity jump is oriented at $\phi_{G F}$ of the fault, tangent to the decollement at point $G$. The law of sines,

$$
\frac{\widehat{\omega} L_{G B}}{\sin \left(\phi_{D}+\phi_{G F}\right)}=\frac{1}{\cos \phi_{G F}}=\frac{\widehat{J}_{G}}{\cos \phi_{D}}
$$

be taken in (6) in the main text. The maximum resisting power is

$$
\begin{aligned}
P_{\mathrm{mr}}(\underline{\widehat{U}})= & L_{A G} C_{D} \cos \phi_{D}+\widehat{\omega} T_{D} \frac{1}{2} L_{G B}^{2} \\
& +C_{G F} \int_{s(G)=0}^{s(F)} \widehat{J}_{G F}\left(s^{\prime}\right) d s^{\prime}
\end{aligned}
$$

provides the value of this rotation rate as well as the magnitude of the velocity jump at point $G$.

The shape of the fault is determined from the same condition that the velocity jump is always at $\phi_{G F}$ from its tangent at any $s$, as illustrated in the left hodogram of Figure $17(\mathrm{~b})$. This condition reads

$$
\tan \left(\theta_{G F}(s)+\phi_{G F}\right)=\frac{L_{A B}-x_{1}-\sin \phi_{D}}{\cos \phi_{D}-\widehat{\omega} x_{2}}
$$

Taking the derivative of (B.16) with respect to $s$ provides the searched expression for the curvature which is finally presented as

$$
\kappa(s)=\frac{\widehat{\omega}}{\widehat{J}_{G F}} \cos \phi_{G F} .
$$

The expression for the external work is still given by (B.11) although the definition of the moments $I_{1 \mathrm{HW}}$ and $I_{2 \mathrm{HW}}$ should the support function being in case 2 along the fault $G F$ by construction. The quadrature in (B.18) is estimated by numerical means. The application of the maximum strength theorem results in the expression for the upper bound found in (6) in the main text.

B.4. Mechanism Numbers 5 and 6: Compaction and Thrusting. The velocity of the back stop is the same as for the other mechanisms. The velocity of the hanging wall is oriented either at $\phi_{G E}$ from the fault $G E$ or at $\phi_{G E}^{*}$ for the foreland and the hinterland vergence, mechanisms 5 and 6 , respectively. The two corresponding hodograms are presented in Figure 18 and the application of the law of sines provides the various velocity norms proposed in (10) in the main text.

One could note that the velocity jump over the compacting fault has been set to the orientation of case 4 , corresponding to the boundary of the cone for compaction and shear. This choice is based on the experience that the optimum velocity field is always observed on such bounding surfaces and not within the cones interior and is not further justified in this contribution.

The external work associated with these two velocity fields reads

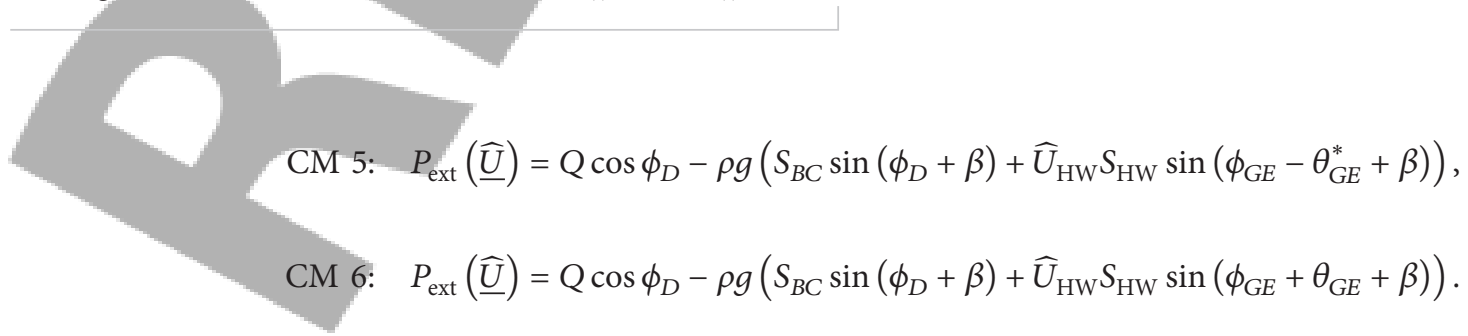




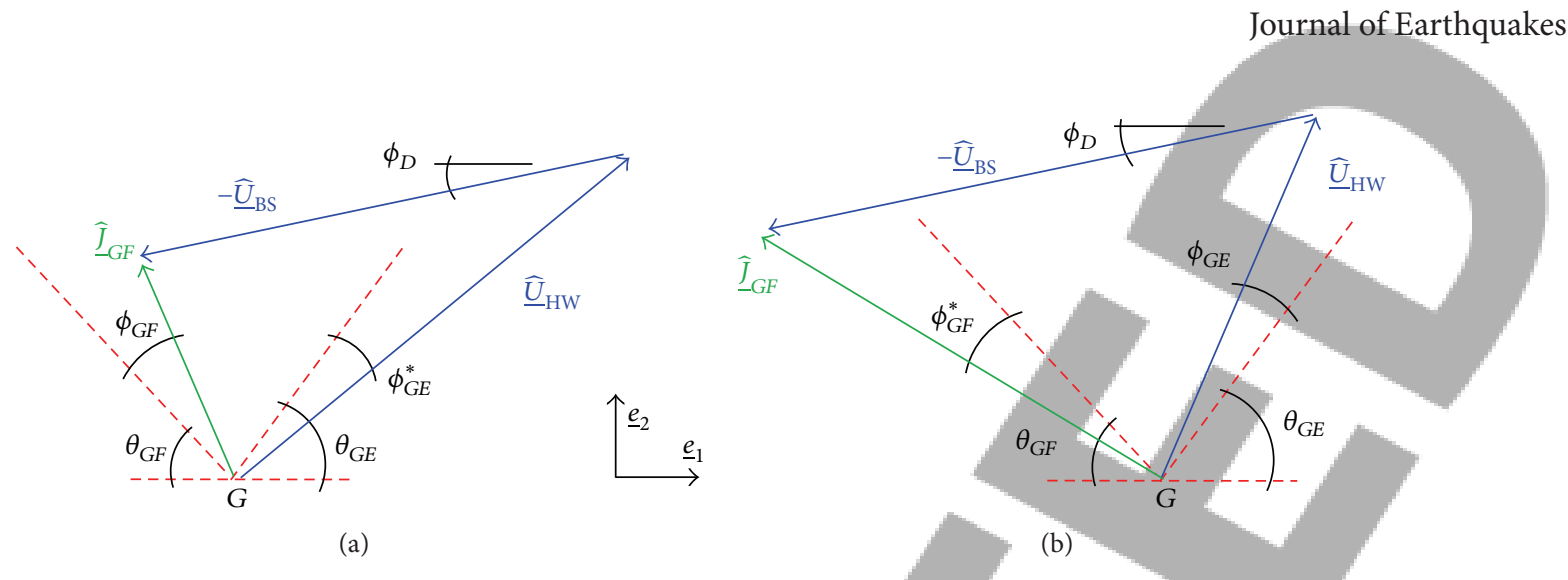

FIGURE 18: The hodograms of the velocity jumps across the faults $G E$ and $G F$ for the compaction mechanism numbers 5 and 6 corresponding to hinterland and foreland vergence in (a) and (b), respectively.

The maximum resisting power is

$$
\begin{aligned}
& \text { CM 5: } \quad P_{\mathrm{mr}}(\underline{\widehat{U}}) \\
&=L_{A G} C_{D} \cos \phi_{D}+C_{G F} \cos \phi_{G F} \widehat{J}_{G F} L_{G F} \\
&+\widehat{U}_{\mathrm{HW}} \sin \phi_{G E}^{*}\left(L_{G E}\left[P_{G E}^{* 0}+\underline{\nabla P}_{G E}^{*} \cdot\left(\underline{x}_{C}-\underline{x}_{G}\right)\right]-\frac{1}{2} L_{G E}^{2} \underline{\nabla P_{G E}^{*}} \cdot \underline{t}_{G E}\right),
\end{aligned}
$$

CM 6: $\quad P_{\mathrm{mr}}(\widehat{\widehat{U}})$

$$
\begin{aligned}
= & L_{A G} C_{D} \cos \phi_{D}+C_{G E} \cos \phi_{G E} \widehat{U}_{H W} L_{G E} \\
& +\widehat{J}_{G F} \sin \phi_{G F}^{*}\left(L_{G F}\left[P_{G F}^{* 0}+\underline{\nabla P}_{G F}^{*} \cdot\left(\underline{x}_{C}-\underline{x}_{G}\right)\right]-\frac{1}{2} L_{G F}^{2} \underline{\nabla P}_{G F}^{*} \cdot \underline{t}_{G F}\right),
\end{aligned}
$$

where $t_{G F}$ and $t_{G E}$ are the unit vectors tangent to the fault indicated in subscript and oriented from $G$ towards the free surface. The expressions for the upper bounds are found in (8) in the main text.

\section{Accretion Wedge}

The velocity field for mechanism numbers 3 and 4 in the accretion wedge relies on a rotation around the point $R$ on the décollement resulting in compaction along the ligament $R E$, Figure 19, and its position of point $R$ is a new unknown. The velocity fields of other parts (back stop and hanging wall) in accretion wedge are similar to those in triangle wedge which has been described in Appendices B.3 and B.4. The hanging wall sustains a rotation $-\widehat{\omega} \underline{e}_{3}$ around point $R$ such that the velocity at ligament $R E$ positioned by the vector $\underline{x}$ is $-\widehat{\omega} \underline{e}_{3} \wedge x_{2} \underline{e}_{2}$. Since the very front of the accretion wedge is stable, the velocity jump at any point $G$ at ligament $R E$ is $-\widehat{\omega} \underline{x}_{2} \underline{e}_{1}$, so that the velocity jump at point $E$ on the surface is $-\widehat{\omega} H \underline{e}_{1}$.

The total external work of mechanism 3 reads

$$
\begin{aligned}
& P_{\text {ext }}(\widehat{\widehat{U}})=Q \cos \phi_{D}-\rho g\left(S_{B C} \sin \left(\phi_{D}+\beta\right)\right. \\
& \left.+\widehat{\omega}\left[\cos \beta\left(L_{A B} S_{\mathrm{HW}}-I_{1 \mathrm{HW}}\right)+\sin \beta I_{2 \mathrm{HW}}\right]\right) .
\end{aligned}
$$

The maximum resisting power of mechanism number 3 is the sum of the support function over the dissipative surfaces, the décollement, the fault $G F$ and the ligament $R E$. The sum of the support function over the dissipative surfaces, the décollement, and the fault $G F$ has been illustrated in (B.5). The gradient compaction strength along the ligament reads

$$
P^{*}=P^{0 *}+G^{*}\left(H-x_{2}\right),
$$

where $G^{*}$ stands for the gradient norm, so that the resisting power of the compaction on the ligament reads

$$
P^{*} \widehat{J}_{R E}=\int_{0}^{H} P^{*} \widehat{\omega} x_{2} d x_{2}=\widehat{\omega}\left(\frac{1}{2} P_{R E}^{0 *} H^{2}+\frac{1}{6} G^{*} H^{3}\right) .
$$

The total maximum resisting power is given

$$
\begin{aligned}
P_{\mathrm{mr}}(\underline{\widehat{U}}) & \\
= & L_{A G} C_{D} \cos \phi_{D}+\widehat{\omega} T_{D} \frac{1}{2} L_{G B}^{2} \\
& +C_{G F}\left(\cos \phi_{G F} \widehat{J}_{G} L_{G F}+\widehat{\omega} L_{G F}^{2} \frac{1}{2} \operatorname{cotan} \phi_{G F}\right) \\
& +\widehat{\omega}\left(\frac{1}{2} P_{R E}^{* 0} H^{2}+\frac{1}{6} G^{*} H^{3}\right) .
\end{aligned}
$$




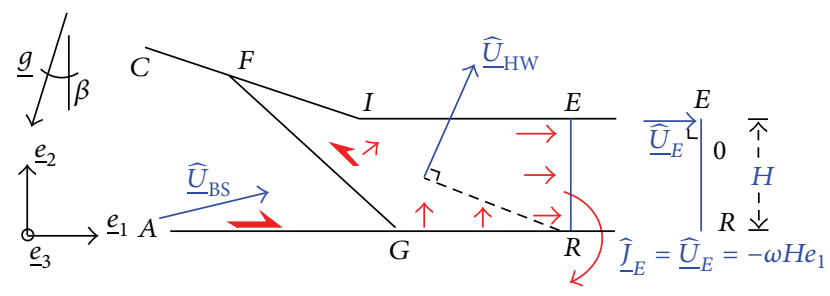

FIGURE 19: The virtual velocity field for collapse mechanism number 3 for accretion wedge and the hodogram of the velocity jump at point E.

Application of the maximum strength theorem then results in the expression for the upper bound of mechanism number 3 found in (13) in the main text.

We can follow the same procedure illustrated above to produce the upper bound of mechanism number 4 in (14) in the main text.

\section{Conflict of Interests}

The authors declare that there is no conflict of interests regarding the publication of this paper.

\section{Acknowledgments}

This research was supported by the National Natural Science Foundation of China (no. 41404075), the CAS/CAFEA International Partnership Program for Creative Research Teams (no. KZZD-EW-TZ-19), and China National Science and Technology Support Program (2012BAK19B03-5). The authors are very grateful to Yves Leroy for providing many advices in the calculation and paper writing. They thank Manuel Pubellier and Alexandra Robert for discussion. They thank two anonymous reviewers for their critical review and suggestion to improve the content and presentation of the paper.

\section{References}

[1] R. A. Price, "The southeastern Canadian Cordillera: thrust faulting, tectonic wedging, and delamination of the lithosphere," Journal of Structural Geology, vol. 8, no. 3-4, pp. 239-254, 1986.

[2] J. Hubbard and J. H. Shaw, "Uplift of the longmen shan and tibetan plateau, and the 2008 wenchuan ( $M=7.9$ ) earthquake," Nature, vol. 458, no. 7235, pp. 194-197, 2009.

[3] D. Jia, G. Wei, Z. Chen, B. Li, Q. Zeng, and G. Yang, "Longmen Shan fold-thrust belt and its relation to the western Sichuan Basin in central China: new insights from hydrocarbon exploration," AAPG Bulletin, vol. 90, no. 9, pp. 1425-1447, 2006.

[4] W. Jin, L. Tang, K. Yang, G. Wan, Z. Lü, and Y. Yu, “Transfer zones within the Longmen Mountains thrust belt, SW China," Geosciences Journal, vol. 13, no. 1, pp. 1-14, 2009.

[5] W. Jin, L. Tang, K. Yang, G. Wan, and Z. Lü, "Segmentation of the long-men mountains thrust belt, Western Sichuan Foreland Basin, SW China," Tectonophysics, vol. 485, no. 1-4, pp. 107-121, 2010.

[6] H. A. K. Charlesworth and L. G. Gagnon, "Intercutaneous wedges, the triangle zone and structural thickening of the mynheer coal seam at coal valley in the rocky mountain foothills of central Alberta," Bulletin of Canadian Petroleum Geology, vol. 33, no. 1, pp. 22-30, 1985.

[7] W. R. Jamison, "Mechanical stability of the triangle zone: the backthrust wedge," Journal of Geophysical Research, vol. 98, no. 11, pp. 20015-20030, 1993.

[8] S. G. Erickson, "Mechanics of triangle zones and passiveroof duplexes: implications of finite-element models," Tectonophysics, vol. 245, no. 1-2, pp. 1-11, 1995.

[9] B. A. Couzens and D. V. Wiltschko, "The control of mechanical stratigraphy on the formation of triangle zones," Bulletin of Canadian Petroleum Geology, vol. 44, no. 2, pp. 165-179, 1996.

[10] W. R. Jamison, "Mechanical models of triangle zone evolution," Bulletin of Canadian Petroleum Geology, vol. 44, no. 2, pp. 180194, 1996.

[11] J. L. Varsek, "Structural wedges in the Cordilleran crust, southwestern Canada," Bulletin of Canadian Petroleum Geology, vol. 44, no. 2, pp. 349-362, 1996.

[12] B. A. Couzens-Schultz, B. C. Vendeville, and D. V. Wiltschko, "Duplex style and triangle zone formation: insights from physical modeling," Journal of Structural Geology, vol. 25, no. 10, pp. 1623-1644, 2003.

[13] J. Adam, D. Klaeschen, N. Kukowski, and E. Flueh, "Upward delamination of cascadia basin sediment infill with landward frontal accretion thrusting caused by rapid glacial age material flux," Tectonics, vol. 23, no. 3, Article ID TC3009, 2004.

[14] D. Montanari, C. Del Ventisette, M. Bonini, and F. Sani, "Passive-roof thrusting in the Messinian Vena del Gesso Basin (Northern Apennines, Italy): constraints from field data and analogue models," Geological Journal, vol. 42, no. 5, pp. 455-476, 2007.

[15] D. C. Tanner, C. Brandes, and B. Leiss, "Structure and kinematics of an outcrop-scale fold-cored triangle zone," AAPG Bulletin, vol. 94, no. 12, pp. 1799-1809, 2010.

[16] J. Salencon, De l'Élasto-Plasticité au Calcul à la Rupture, École Polytechnique, Palaiseau, and Ellipses, Paris, France, 2002.

[17] F. A. Dahlen, "Noncohesive critical coulomb wedges: an exact solution," Journal of Geophysical Research, vol. 89, no. 12, pp. 10125-10133, 1984.

[18] B. Maillot and Y. M. Leroy, "Kink-fold onset and development based on the maximum strength theorem," Journal of the Mechanics and Physics of Solids, vol. 54, no. 10, pp. 2030-2059, 2006.

[19] N. Cubas, Y. M. Leroy, and B. Maillot, "Prediction of thrusting sequences in accretionary wedges," Journal of Geophysical Research: Solid Earth, vol. 113, no. 12, pp. 1-21, 2008.

[20] D. Bossort, "Relationship of the porcupine hills to early laramide movements," in Guidebook 7th Annual Field Conference Waterton, pp. 46-51, Alberta Society of Petroleum Geologists, 1957.

[21] I. R. Vann, R. H. Graham, and A. B. Hayward, "The structure of mountain fronts," Journal of Structural Geology, vol. 8, no. 3-4, pp. 215-227, 1986.

[22] B. Fu, P. Shi, H. Guo, S. Okuyama, Y. Ninomiya, and S. Wright, "Surface deformation related to the 2008 Wenchuan earthquake, and mountain building of the Longmen Shan, eastern Tibetan Plateau," Journal of Asian Earth Sciences, vol. 40, no. 4, pp. 805-824, 2011. 

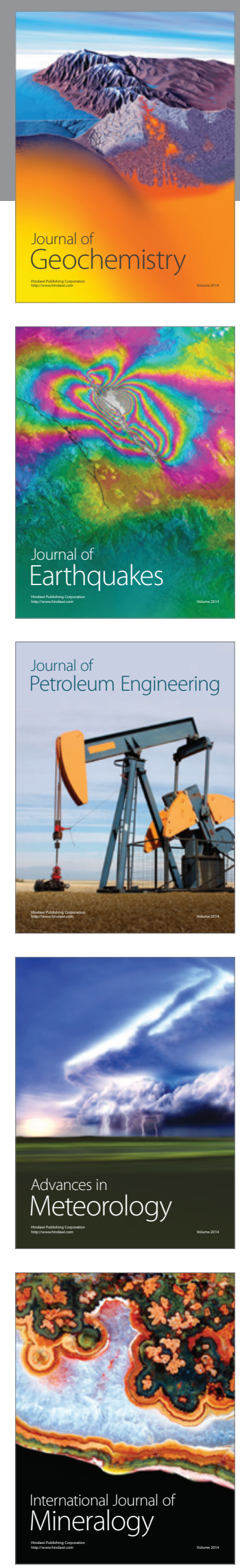
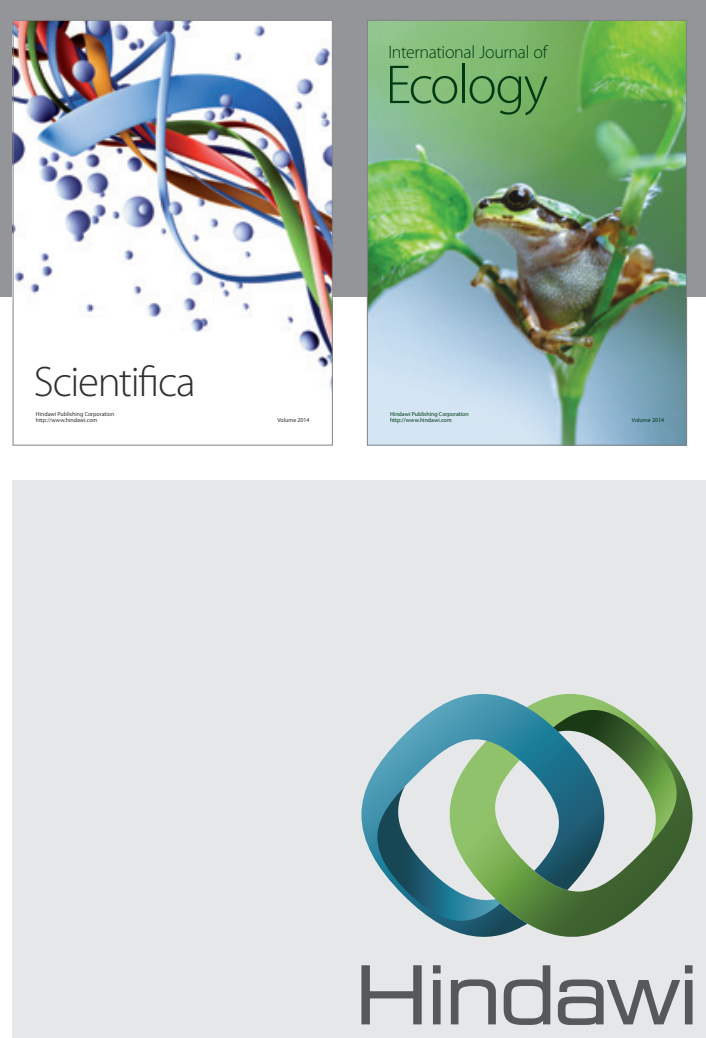

Submit your manuscripts at

http://www.hindawi.com
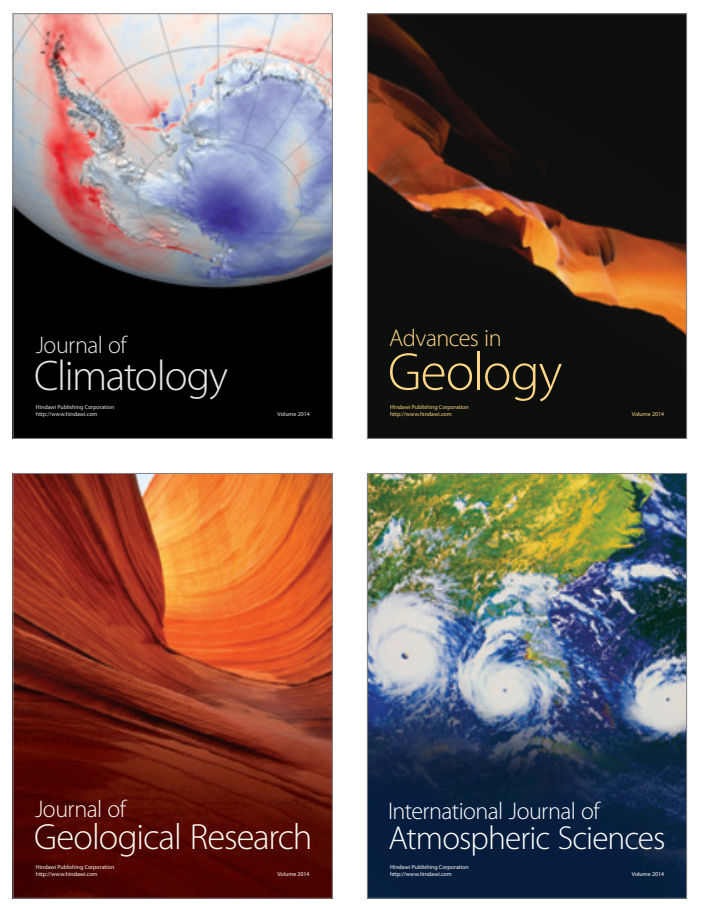

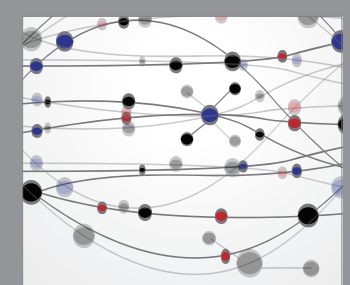

The Scientific

\section{World Journal}
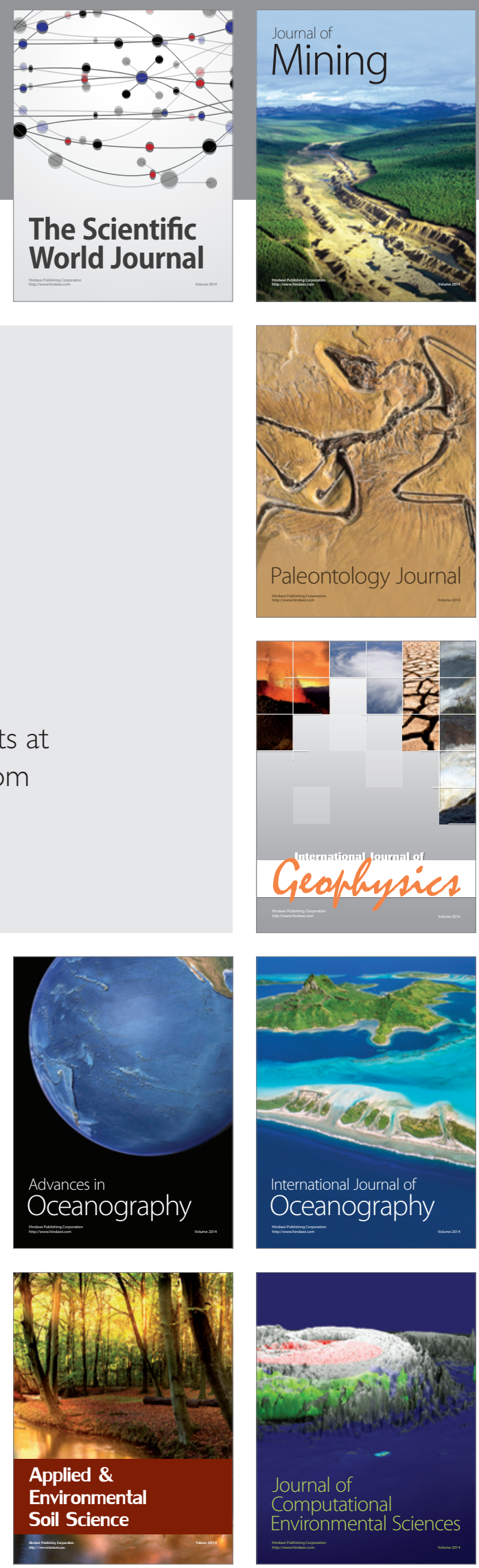